\title{
CAMA
}

Centre for Applied Macroeconomic Analysis

\section{The Asymmetric Effects of Uncertainty Shocks}

\section{CAMA Working Paper 72/2020 August 2020}

\section{Valentina Colombo}

Department of Economics, University of Bologna

Centre for Applied Macroeconomic Analysis, ANU

\section{Alessia Paccagnini}

Michael Smurfit Business Graduate Business School, University College Dublin Centre for Applied Macroeconomic Analysis, ANU

\section{Abstract}

This study evaluates the effects of financial uncertainty shocks in the US, investigating the role of the monetary policy stance. Estimating a nonlinear Vector Autoregressive, we find that an uncertainty shock triggers asymmetric and negative effects across the business cycle. The reactions of consumption and investments are state-dependent and drive the fluctuations of GDP. The variance of macroeconomic variables due to the shock is from four to six times larger in recessions than in normal times. A counterfactual exercise shows that the Balance Sheet-related monetary policy mitigates the persistence and the magnitude of the recessionary effects of the shock. 


\section{Keywords}

Uncertainty, Smooth Transition VAR, Nonlinearities, Monetary Policy

\section{JEL Classification}

C50, E32, E52

\section{Address for correspondence:}

(E) cama.admin@anu.edu.au

\section{ISSN 2206-0332}

The Centre for Applied Macroeconomic Analysis in the Crawford School of Public Policy has been established to build strong links between professional macroeconomists. It provides a forum for quality macroeconomic research and discussion of policy issues between academia, government and the private sector.

The Crawford School of Public Policy is the Australian National University's public policy school, serving and influencing Australia, Asia and the Pacific through advanced policy research, graduate and executive education, and policy impact. 


\title{
The Asymmetric Effects of Uncertainty Shocks
}

\author{
Valentina Colombo* Alessia Paccagnini ${ }^{\dagger}$
}

\begin{abstract}
This study evaluates the effects of financial uncertainty shocks in the US, investigating the role of the monetary policy stance. Estimating a nonlinear Vector Autoregressive, we find that an uncertainty shock triggers asymmetric and negative effects across the business cycle. The reactions of consumption and investments are state-dependent and drive the fluctuations of GDP. The variance of macroeconomic variables due to the shock is from four to six times larger in recessions than in normal times. A counterfactual exercise shows that the Balance Sheet-related monetary policy mitigates the persistence and the magnitude of the recessionary effects of the shock.
\end{abstract}

JEL classification: C50, E32, E52

Keywords: Uncertainty, Smooth Transition VAR, Nonlinearities, Monetary Policy

${ }^{*}$ Department of Economics, University of Bologna, and Center for Applied Macroeconomic Analysis. Email: valentina.colombo3@unibo.it.

${ }^{\dagger}$ Michael Smurfit Business Graduate Business School, University College Dublin, and Center for Applied Macroeconomic Analysis. Email: alessia.paccagnini@ucd.ie. 


\section{Introduction}

Uncertainty is recognized as one of the main causes of the protracted recession in the United States (Stock and Watson, 2012). As illustrated in the theoretical literature, a rise in uncertainty can affect the economy through the "real-option effects" (Bernanke, 1983; Dixit and Pindyck, 1994), precautionary savings (Basu and Bundick, 2017), or increasing financing costs (Pastor and Veronesi, 2013; Gilchrist, Sim, and Zakrajsek, 2014).

The empirical literature provides evidence of recessionary effects of uncertainty shocks, see Bloom (2009) and Castelnuovo (2019a) for a survey. In the main, this evidence has been produced relying on linear Vector Autoregressive (VAR) models (Bloom, 2009; Jurado, Ludvigson, and Ng, 2015; Rossi and Sekhposyan, 2015; Baker, Bloom, and Davis, 2016; Leduc and Liu, 2016, among many others). However, empirical studies highlight that the macro-financial linkages may be nonlinear. Angelini, Bachiocchi, Caggiano, and Fanelli (2019) show that nonlinear models provide evidence of a more powerful propagation mechanism for shocks in extreme conditions (i.e., recessions and the global financial crisis).

We contribute to the literature by investigating whether uncertainty shocks affect asymmetrically macroeconomic variables over the business cycle in the US. Our focus is the monetary policy stance and how different monetary tools tackle the uncertainty shocks. A non linear VAR is estimated considering an exogenous uncertainty shock which affects macroeconomic variables conditional on the states of the economy (recessions versus normal times). The uncertainty shock is identified by appealing to the financial uncertainty indicator proposed by Ludvigson, Ma, and Ng (2019). We provide novel empirical evidence for the US investigating the role of the monetary policy as a transmission channel. In order to do this, in addition to the key macroeconomic variables, we include short-term and long-term interest rates and the Federal Reserve's Balance Sheet as monetary policy tools. 
A few papers investigate the nonlinear relation between monetary policy and uncertainty shocks (Aastveit, Natvik, and Sola, 2017; Caggiano, Castelnuovo, and Pellegrino, 2017; Caggiano, Castelnuovo, and Nodari, 2020; Jackson, Kliesen, and Owyang, 2019). However, such contributions focus on the role of the short-term interest rate. Conversely, we focus on the Balance Sheet-related monetary policy. Our decision to do this is motivated by the fact that Balance Sheet-related monetary policy may be considered an important future component of the monetary toolkit of the Federal Reserve (Dell'Ariccia, Rabanal, and Sandri, 2018).

How does the uncertainty propagate into the economy? Does the Balance Sheetrelated monetary policy tackle the recessionary effects of uncertainty shocks? We answer these questions by including the post-World War US quarterly data in a Smooth Transition VAR, focusing on the monetary policy. We find systematic asymmetries across the business cycle in response to uncertainty shocks. These shocks play an important role in deepening the macroeconomic activity, depending on which phase of the business cycle the economy is in when the uncertainty shock occurs. We also find that the shock triggers demand-type dynamics in recessions but not in normal times.

The reaction of the Federal Reserve is consistent with an inflation-targeting strategy pursued by the monetary policymakers. In recessions our (Generalised) impulse responses predict a reaction of the Federal Reserve via an increase in the total assets of the Federal Reserve Balance Sheet of more than $2 \%$ with respect to the pre-shock level. Disentangling the propagation channels, we provide evidence of how consumption and investments are driving the GDP to fall in the short- and medium-run, in particular during recessionary periods. Among the disaggregate components of consumption and investments, we document an important difference in the reaction of durable consumption and residential investments across the business cycle, with the latter showing an "overshooting" behavior.

According to the forecast error variance decomposition, the variance of macroe- 
conomic variables (GDP, consumption, investments, and unemployment) explained by the shock is from four to six times larger in recessions than in normal times.

A counterfactual exercise provides evidence of the role of Balance Sheet-related monetary policies in mitigating the macroeconomic fluctuation due to uncertainty shock. In absence of Balance Sheet-related monetary policies, the effects of the financial uncertainty shock would become more persistent and larger (in absolute values) than the effects estimated in the baseline.

The remainder of the paper is organized as follows. Section 2 reviews the literature, while Section 3 describes the data and the empirical analysis. Section 4 present the results. Section 5 illustrates the propagation channels and the Generalized Forecast Error Variance Decomposition. Section 6 describes the counterfactual experiment and Section 7 presents the conclusions.

\section{Related Literature}

This study is connected to the empirical literature which investigates the impact of the uncertainty on macroeconomic variables (Bloom, 2009; Jurado, Ludvigson, and Ng, 2015; Rossi and Sekhposyan, 2015; Baker, Bloom, and Davis, 2016; Ludvigson, Ma, and Ng, 2019, among others). In particular, our research fits within the burgeoning literature illustrating that uncertainty shocks have regime-dependent effects. For instance, Cacciatore and Ravenna (2020) show that deviations from efficient wage setting due to matching frictions in the labor market, combined with a binding downward wage rigidity, generate state-dependent amplification of uncertainty shocks. Empirical evidence is documented, for example, by Caggiano, Castelnuovo, and Groshenny (2014).

Our focus on financial uncertainty is justified both theoretically and empirically. While from a theoretical standpoint Basu and Bundick (2017) show that financial uncertainty is an important driver of the business cycle in a microfounded macroeco- 
nomic framework, empirical studies provide evidence of the exogeneity of financial shock to the business cycle (see Carriero, Clark, and Marcellino, 2018; Angelini, Bachiocchi, Caggiano, and Fanelli, 2019; Ludvigson, Ma, and Ng, 2019).

Our contribution corroborates previous papers on the nonlinear relationship between uncertainty and the stance of the monetary policy. Aastveit, Natvik, and Sola (2017) and Caggiano, Castelnuovo, and Pellegrino (2017) estimate an Interacted VAR model to investigate the asymmetric effects of uncertainty on the business cycle. In particular, Aastveit, Natvik, and Sola (2017) show how the short-term interest rate is less effective when uncertainty is high. At the same time, Caggiano, Castelnuovo, and Pellegrino (2017) document that uncertainty shocks trigger a deeper recession during the Zero Lower Bound (ZLB) period than in normal times. Caggiano, Castelnuovo, and Nodari (2020), relying on a Smooth Transition VAR, quantify the effects of a VXO shock in good and bad times. They find that the systematic monetary policy is more effective in good times than in bad times. Jackson, Kliesen, and Owyang (2019), estimating a time-varying Threshold VAR, find asymmetric effects of economic policy uncertainty shocks under high and low uncertainty regimes. They find that the systematic monetary policy plays an important role in offsetting the adverse effects of the uncertainty shock.

However, these papers fail to scrutinize the stance of the monetary policy, relying on the Balance Sheet-monetary policy in addition to the short and long-term interest rates as monetary policy instruments.

For this reason, our study is also connected to the literature on the Central Bank's Balance Sheet going back to the seminal research of Bernanke and Gertler (1989), Kiyotaki and Moore (1997), and . Bernanke, Gertler, and Gilchrist (1999). In particular, we contribute to the recent strand of the empirical literature that discusses the relevance of the monetary policy tools related to the Central Bank's Balance Sheet (Curdia and Woodford, 2011).

We include the Balance Sheet-related monetary policy instrument inspired by 
Bernanke (2012) that points out that the Federal Reserve's Balance Sheet has been used by the Fed as a tool for achieving its mandated objectives of maximum employment and price stability. ${ }^{1}$ Moreover, our decision is supported by the contributions of Gambacorta, Hofmann, and Peersman (2014) and Dahlhaus, Hess, and Reza (2018). Gambacorta, Hofmann, and Peersman (2014) estimate a panel VAR including the total assets of Fed Balance Sheet as the main policy instrument for many advanced economies such as the Euro Area and the US. They document how an expansionary monetary policy shock leads to a significant rise in macroeconomic variables. Dahlhaus, Hess, and Reza (2018), relying on a factor-augmented vector autoregression, investigate the effects of US Federal Reserve quantitative program on the Canadian economy. They find that the Fed's Balance Sheet has an important effect on Canadian GDP. Their decision on the choice of this monetary policy tool is motivated by the fact that the Balance Sheet holdings contain information on quantitative easing (QE) and are unaffected by closely related non-QE policies, such as forward-guidance. This aspect is relevant since the Fed has often announced information on multiple unconventional monetary policies at the same time. Moreover, the effects of a QE program can be captured by the movements in the Balance Sheet holdings of long-term assets through the signaling and portfolio rebalancing channels of transmission.

In contrast with Gambacorta, Hofmann, and Peersman (2014) and Dahlhaus, Hess, and Reza (2018) who identify a monetary policy shock, we consider the total assets of the Fed Balance Sheet as a transmission mechanism through which financial uncertainty shock affects the business cycle. Moreover, these researchers estimate linear models focusing on the ZLB regime. Conversely, our nonlinear estimation allows us to consider a longer sample and to randomize over histories (i.e., during

\footnotetext{
1"In using the Federal Reserve's balance sheet as a tool for achieving its mandated objectives of maximum employment and price stability, the FOMC has focused on the acquisition of longerterm securities-specifically, Treasury and agency securities, which are the principal types of securities that the Federal Reserve is permitted to buy under the Federal Reserve Act" (Bernanke, 2012).
} 
recessions and normal times).

\section{Data and Methodology}

In this Section we describe data and introduce the Smooth Transition VAR model.

\subsection{Data}

We study the effects of uncertainty shock in the US across the business cycle. We use quarterly data from 1960Q3 through 2019Q4. The series are transformed to induce stationarity. The main measures of real activity are the first difference of log real GDP (GDP) and the unemployment rate (Unempl). Inflation (Infl) is measured by the first difference of log personal consumption expenditures chain price index. We use the effective federal funds rate (FFR) as a measure of the short-term interest rate. To proxy the Balance Sheet-related monetary policy, we rely on the first difference of log total assets of the Fed Balance Sheet (BS), as in Gambacorta, Hofmann, and Peersman (2014). ${ }^{2}$ Since such a measure is only downloadable from the Federal Reserve of St. Louis from 2002, we collect monthly data of the total assets of the Fed's BS for the previous periods (1960-2001) retrieving the information from the monthly Federal Bulletins. Then, we convert monthly data into quarterly observations via quarterly averaging. In addition, we include the 10-year Treasury bond long-term interest rates (10-y TB). This long-term interest rate is important in the transmission mechanism of BS related monetary policy on macroeconomic variables (Kiley, 2018). Moreover, including the long-term interest rate allows us

\footnotetext{
${ }^{2}$ The Federal Reserve faced the Great Recession by adopting an extraordinarily expansionary monetary policy stance, lowering policy rates to stimulate the economy. However, with monetary policy rates close to the ZLB, when further stimulus was needed, Central Banks turned to noninterest rate, or non-standard policy measures. Meaning and Zhu (2011) use the Federal Reserve balance sheet information to proxy the unconventional monetary policy tools. Peersman (2011) studies the (linear) macroeconomic effects of unconventional monetary policy in the Euro Area relying on the size of European Central Bank (ECB)'s BS. Also, Gambacorta, Hofmann, and Peersman (2014) focus on the total assets of the Central Bank's BS to proxy unconventional monetary policies.
} 
to consider the impact of forward guidance (Bundick and Herriford, 2017). ${ }^{3}$

We proxy the financial uncertainty using the recent measure proposed by Ludvigson, Ma, and Ng (2019). This factor model-based indicator provides proxies for uncertainty computed for h-step-ahead forecast errors. In our analysis, we include the uncertainty measure (Unc) with forecast horizon at 3-months, converting it to quarterly figures by taking the average value in each quarter. Figure 1 plots the uncertainty measures versus the National Bureau of Economic Research (NBER) turning points (shaded area). It can be observed that financial uncertainty spikes occur during recessionary periods. From our perspective, this indicator has two main advantages. First, as argued by Ludvigson, Ma, and Ng (2019), it captures changes in the financial market uncertainty that are a source of economic fluctuations, rather than being an endogenous response to fundamentals. Angelini, Bachiocchi, Caggiano, and Fanelli (2019) confirm, empirically, such exogeneity of the financial uncertainty indicator. Second, this index is more suitable than the VIX which is widely used for proxing uncertainty. Indeed, as stressed by Bekaert, Hoerova, and Lo Duca (2013), this indicator could be more reflective of countercyclical risk aversion than uncertainty. The above reasons make the Ludvigson, Ma, and $\mathrm{Ng}$ (2019) indicator more appealing for our analysis, especially in identifying the shock. ${ }^{4}$

In Section 5 we investigate the channels through which uncertainty propagates. In doing so, we augment the baseline specification by the first difference of log real gross private domestic investment (Inv) and of real personal consumption expenditures (Cons). Then, we disaggregate consumption (services, non-durables, and durables goods), and investment series (inventories, residential, and nonresidential

\footnotetext{
${ }^{3}$ Gürkaynak, Sack, and Swanson (2005) show that the Federal Reserve has relied on communication to affect agents' expectations over future policy moves to influence long-term rates. Adrian, Crump, and Moench (2013) argue that after the Federal Open Market Committee (FOMC) of August 9, 2011, in which the Committee announced "exceptionally low levels for the federal funds rate at least through mid-2013" the term premia in longer-horizon TB declined significantly.

${ }^{4}$ Appendix D shows the robustness of our results using the VXO as an alternative measure of uncertainty (Bloom, 2009).
} 
investments).

The choice of the quarterly frequency is justified by our interest in the response of (among other variables) GDP and investment, which are not available at a monthly frequency. The start date of our sample is restricted by the availability of the uncertainty indicator.

The financial uncertainty indicator of Ludvigson, Ma, and Ng, 2019 can be downloaded from https://www.sydneyludvigson.com/data-and-appendixes. The data are seasonally adjusted and retrieved from the Federal Reserve Bank of St. Louis, unless indicated otherwise.

\subsection{Methodology: A Smooth Transition VAR}

The estimated Smooth-Transition VAR model (STVAR) is defined as follows:

$$
\begin{aligned}
X_{t} & =F\left(z_{t}\right) \Pi_{R}(L) X_{t}+\left(1-F\left(z_{t}\right)\right) \Pi_{N T}(L) X_{t}+\varepsilon_{t}, \\
\varepsilon_{t} & \sim N\left(0, \Omega_{t}\right), \\
\Omega_{t} & =F\left(z_{t}\right) \Omega_{R}+\left(1-F\left(z_{t}\right)\right) \Omega_{N T}, \\
F\left(z_{t}\right) & =\exp \left(-\gamma z_{t}\right) /\left(1+\exp \left(-\gamma z_{t}\right)\right), \gamma>0, z_{t} \sim N(0,1) .
\end{aligned}
$$

where $X_{t}$ is a set of endogenous variables, $\Pi(L)_{R}$ and $\Pi(L)_{N T}$ are the polynomial matrices in the lag operator L capturing the dynamics of the system during recessions and normal times, respectively. The vector of reduced-form residuals $\left(\varepsilon_{t}\right)$ has a zero-mean and heteroskedastic, state-contingent variance-covariance matrix $\Omega_{t}$, where $\Omega_{R}$ and $\Omega_{N T}$ refer to the covariance structure of the residuals in recessions and normal times, respectively. $F\left(z_{t}\right)$ is a logistic and continuous function bounded between zero and one which depends on the state variable $z_{t}$. The slope parameter $\gamma$ dictates how smooth the transition is from one regime to another, i.e. from recessions to normal times and vice versa. If $\gamma \rightarrow \infty$ in (4), then the transition 
from one state of economy to the other is abrupt. Conversely, a small value of $\gamma$ implies that such a transition is smooth.

Our vector is $X_{t}=[\operatorname{Infl}, G D P, U n e m p l, F F R, B S, 10-y T B, U n c]^{\prime}$. The uncertainty shock is identified via the Cholesky decomposition, with the sample assumptions provided by Christiano, Eichenbaum, and Evans (2005) and widely adopted in the monetary policy literature. In other words, the slow-moving variables (Infl, GDP, and Unempl) are ordered first, whereas the fast moving variables (monetary policy tools) are ordered last. This ordering implies that monetary policies depend on the real activities. In setting the monetary policy tools, we place the total assets of the Fed BS after the effective federal fund rate (FFR) and before the 10-year Treasury bond (10-y TB). This reflects the idea that the primary monetary policy tool is the short-term interest rate. The uncertainty measure is set last in vector $X_{t}$. This means that we "purge" our uncertainty indicator from the contemporaneous movements of our macroeconomic variables, therefore sharpening the identification of uncertainty shocks. This identification implies that macroeconomic variables react to uncertainty shocks with a lag. ${ }^{5}$

The transition variable $z_{t}$ and the calibration of the smoothing parameter $\gamma$ are justified as follows. As in Auerbach and Gorodnichenko (2012) and Caggiano, Castelnuovo, Colombo, and Nodari (2015), we employ a standardized backwardlooking moving average of the output growth rate, involving eight realizations of the quarter-on-quarter real GDP growth rate. $^{6}$ We calibrate the smoothness parameter $\gamma$ to match the probability of being in recessions as identified by the NBER business cycle dates ( $15 \%$ in our sample). The recessionary phase is defined as a

\footnotetext{
${ }^{5}$ The main results are not affected when the uncertainty index is set as the first variable in the vector $X_{t}$. The results are reported in Appendix D.

${ }^{6}$ The transition variable $z_{t}$ has been standardized to be comparable to those employed in the literature. To choose the transition variable we follow the heuristic rule suggested by Teräsvirta (1988). We perform the linearity test relying on different potential transition variables, such as the lagged (t-1) standardized backward looking moving average (MA) over (j) quarter(s) of the output growth rate with $j \in J=2, \ldots 12$ and we choose the transition variable for which the $\mathrm{p}$-value is minimized. This is because whether there is a correct transition variable among the different alternatives, the power of the test is maximized against it. Moreover, our results are robust using a moving average over six quarters. See Appendix D for details.
} 
period in which $\operatorname{Pr}\left(F\left(z_{t}\right) \geqslant 0.85\right) \approx 15 \%$. This means that the economy spends about $15 \%$ of the time in recessions and $85 \%$ in normal times. This implies setting $\gamma=2.1$. The choice is consistent with the threshold value $\bar{z}=-1 \%$ discriminating between recessions and normal times. In particular, if the realizations of the standardized transition variable $z_{t}$ is lower (higher) than the threshold value $\bar{z}$, it will be associated to recessions (normal times). Figure 2 plots the transition function $F\left(z_{t}\right)$ versus the NBER turning points and shows that high values of $F\left(z_{t}\right)$ tend to be associated with NBER recessions.

Given the high nonlinearity of the model, we estimate the STVAR in (1) relying on the Markov-Chain Monte Carlo simulation of Chernozhukov and Hong (2003) (see Appendix B for details). To model the endogeneity of the transition from one state to another after an uncertainty shock occurs, we compute the Generalized Impulse Response Functions (GIRFs) proposed by Koop, Pesaran, and Potter (1996). Since the GIRFs depend on the initial condition, we study the evolution of the GIRFs over histories (i.e., during recessions and normal times). We estimate a nonlinear VAR including two lags, as suggested by the Akaike information criterion. Our model includes a constant.

Before estimating the STVAR in (1), we perform a linearity test. Linearity is tested by replacing the transition variable $\left(z_{t}\right)$ by the first and the third order Taylor series approximation around $\gamma=0$, as suggested by Teräsvirta and Yang (2014). We perform an LM test that suggests a strong rejection of the linearity for the system as a whole in favor of a STVAR (details in Appendix A).

\section{Results}

Figure 3 plots the Generalised IRFs (GIRFs) of the modeled variables to a onestandard deviation unexpected increase in uncertainty in recessions (first column) and in normal times (second column). As in Colombo and Paccagnini (2020), such 
an increase is constant across regimes, given that our aim is to highlight differences in dynamics conditional on the same size of the shock. ${ }^{7}$ Shaded bands denote confidence intervals at $68 \%$ levels. The log difference transformed variables have been accumulated (inflation, GDP, and total assets of the Fed Balance Sheet). The horizontal axis identifies quarters, whereas the vertical axis is expressed in percentage points.

Uncertainty shocks have asymmetric effects across the business cycle. The phase of the business cycle in which the economy is when uncertainty shocks occur affect the size of the reaction of macroeconomic variables. The shock triggers negative macroeconomic fluctuations in recessions and in normal times. However, the effects of the shock on the macroeconomic activity more than double when uncertainty shocks occurr in recessions.

In normal times, an exogenous increase in uncertainty negatively affects the GDP with a trough response of $-0.2 \%$, and then returns to the steady-state. The response of unemployment is qualitatively similar to the GDP, even though its reaction is relatively more enduring. The reaction of inflation is not as statistically significant as that of the Federal Reserve. However, the reaction of the long-term interest rate to the shock is negative, statistically significant, albeit small.

In recessions, uncertainty shocks increase the unemployment rate $(0.3 \%)$ by reducing aggregate demand $(-0.4 \%)$. Since uncertainty depresses aggregate demand, it also has a long-lasting deflationary effect. In line with their inflation-targeting strategy, monetary policymakers lower the nominal interest rate to alleviate the recessionary effects of uncertainty. Interestingly, the generalized impulse responses also predict a reaction of the Federal Reserve via an increase in the total assets of the Fed Balance Sheet (2\%). Financial uncertainty has a negative and statistically

\footnotetext{
${ }^{7}$ The unexpected increase in uncertainty is calibrated with the one-standard deviation uncertainty shock estimated in recessions. Our results are materially the same if we use the one-standard deviation uncertainty shock estimated in normal times. Moreover, our results are qualitatively similar when we include a regime-specific covariance matrix (eq. (3)), thus allowing for changes in the size of the shocks (as well as the transmission mechanisms) between normal times and recessions. Results are available upon request.
} 
significant impact not only on short-term but also on long-term interest rates, with a double impact on the latter. The expansionary monetary policy predicted by our results corroborates those found in the literature (i.e., Bekaert, Hoerova, and Lo Duca, 2013; Caggiano, Castelnuovo, and Groshenny, 2014; Caggiano, Castelnuovo, and Pellegrino, 2017; Jackson, Kliesen, and Owyang, 2019).

The reaction of the 10-year TB to a financial shock is also found in Castelnuovo (2019b) who, analyzing a linear framework, highlights the stronger reaction of the short end of the term structure with respect to the long one. Conversely, we find the opposite results: after an uncertainty shock, the response of the long-term interest rate (10-year TB) is stronger than the short-term one (FFR). Such a result holds both in recessions and in normal times, although in recessions it is magnified. Our findings may depend on two mechanisms that increase the demand for bonds. Firstly, an increase in uncertainty in both states of the economy may induce households to reduce consumption and increase precautionary savings. The increase in the demand for bonds pushes up the bond prices and depresses the bond yields. Secondly, uncertainty shock has recessionary effects on macroeconomic activity. In recessions, the Fed reacts by cutting the FFR and buying long-term TBs that increase the total assets held in the Fed's BS (as shown in row 5 of the Figure 3). This further increase in demand for bonds depresses government yields even more. We think that in recessions both channels are present and this explains the reason why financial uncertainty shocks have (in absolute value) stronger effects on the long-term interest rate than on the short-term rate.

Our results corroborate those reported in previous contributions on the "demand" type of effects triggered by uncertainty shocks in the US economy, associated with a fall in output and prices at the same time (i.e., Bloom, 2009; Baker, Bloom, and Davis, 2016; Leduc and Liu, 2016; Colombo, 2013; Alessandri and Muntaz, 2019). Our findings are supported by theoretical studies (i.e., Basu and Bundick, 2015) which document that when the price adjusts slowly to changing 
economic conditions, a Real Business Cycle (RBC) model can replicate the recessionary effects of an uncertainty shock. In addition, our work is also supported by the empirical analysis in which uncertainty shocks are found to trigger asymmetric effects across the business cycle (i.e., Nodari, 2014; Caggiano, Castelnuovo, and Pellegrino, 2017; Jackson, Kliesen, and Owyang, 2019), and in particular on unemployment (Caggiano, Castelnuovo, and Groshenny, 2014).

Statistical evidence in favor of asymmetries across regimes. Are the reactions of macroeconomic variables to uncertainty shocks statistically significant different across regimes? The third column of Figure 3 reports the empirical density of the difference between the reaction of macroeconomic variables across regimes. The empirical density is based on 500 realizations of such differences for each horizon $h$. If the zero lines are not included in the confidence bands, then there will be evidence of state-dependent reactions. Our findings confirm that quantitatively the responses are different across regimes from a statistical point of view.

We check the robustness of our findings against several perturbations of the baseline STVAR model. In particular, we focus on alternative i) calibration of smoothness parameters; ii) transition variable; iii) measures of uncertainty; iv) sample size; and v) specifications. Results are reported in Figure D.1 and Figure D.2 in Appendix D.

\section{Propagation Channels}

This Section examines the propagation channels through which uncertainty shock affects GDP. We add consumption or investment, one at a time, into the baseline model. In both specifications, consumption and investments are adequately transformed in the first difference log and placed after GDP in the set of endogenous variables $\left(X_{t}\right)$. This investigation is useful for understanding how the uncertainty shock can be transmitted to the business cycle and how the propagation mechanism 
works differently in the two states of economy (recessions and normal times). Our decision to include these variables relies on several studies that propose models and theoretical frameworks including consumption and/or investments to explain how uncertainty shocks could affect macroeconomic variables (see for instance, Bernanke, 1983; Dixit and Pindyck, 1994; Pastor and Veronesi, 2013; Gilchrist, Sim, and Zakrajsek, 2014; Leduc and Liu, 2016; Basu and Bundick, 2017). Figure 4 and 5 report the responses to the uncertainty shock for consumption and investments, respectively. In the first and the second columns, we show the reaction in normal times and in recessions, while we report their difference in the third column.

An increase to the uncertainty shock is followed by a down-turn in the shortand medium-run of $0.25 \%$ for the aggregate consumption in recessions as pictured in the first line of Figure 4. Meanwhile, in case of normal times, the consumption decreases slowly and reaches the down-turn, around $-0.20 \%$, at the eighth quarter. After this, we investigate how uncertainty propagates through disaggregated measures of consumption, including spending in services, non-durables, and durable consumption components as shown in the second, third, and fourth lines of Figure 4. In recessions, the decrease in consumption is driven by the fall in all three components. In particular, the durable consumption fall is around $-1 \%$ before the fourth quarter. In normal times, results confirm how the response of consumption is mild for services and non-durables. However, in the case of durable consumption, we do not report a statistically significant response to the shock. This evidence of a severe impact of uncertainty during recessionary periods, in particular for durables, is also confirmed by the difference reported in the third column of Figure 4. Our results corroborate the findings of a larger magnitude and more persistent contraction in durable consumption documented by Jackson, Kliesen, and Owyang (2019). We can also report that GDP and consumption spending have a similar reaction to the uncertainty. After the shock hits, we document a fall in both variables which increase slowly after four quarters. This evidence is in line with the behavior of households 
to reduce precautionary spending, in particular on durable goods. These findings confirm that uncertainty shock is a demand shock which reduces the aggregate output via precautionary savings (for reference, see Bloom, Floetotto, Jaimovich, Saporta-Eksten, and Terry, 2018).

The aggregate investments experience a severe fall and subsequent quick increase in recessions. However, in normal times, the impact of the uncertainty shock is weaker and not statistically significant. The first line of Figure 5 shows how the response to an uncertainty shock falls by $2 \%$ in the short run. After one year, the response rapidly increases to become positive. Hence, we investigate how uncertainty propagates through disaggregated measures of investments including inventories, nonresidential, and residential components as shown in the second, third, and fourth lines of Figure 5. The response of aggregate investments is confirmed by the disaggregate components, with the same statistically significant pattern only in recessions, apart from nonresidential investments, which have a statistically significant response for a few quarters in normal times. It is interesting to note how residential investments recover to a steady state with a quick increase which suggests an "overshooting effect". This evidence of a severe impact of uncertainty during recessionary periods, in particular for residential and nonresidential components, is also confirmed by the difference reported in the third column of Figure 5. The rapid decrease, after the uncertainty shock hits, is not a surprising result, since investment is the most volatile component of the GDP. When uncertainty increases, firms freeze their economic activity and investments decrease. As documented in the baseline model, after an increase in uncertainty shock, GDP decrease as well as consumption and investments. If consumption increases at the same rate as the GDP growth rate, investment has quickly changes to an increased pattern showing the overshooting effect. For investments, we can report a behavior known as "wait-and-see" (see for reference Bloom, Bond, and Van Reenen, 2007; Bloom, 2009; Stokey, 2016). In the first three-quarters investments reach their minimum and after that, when the 
temporary uncertainty is solved and the economic situation appears brighter, investments quickly increase. As discussed in Bloom (2009) and in Ferrara, Lhuissier, and Tripier (2018), we can motivate the overshooting pattern looking at the massive comeback of the allocation of labor and capital injected in investment projects that were previously suspended, as happened during the Great Recession. These results provide evidence of how the business activities are quicker to adapt to an uncertain framework than consumption. We can also document how the increase in production is slower than the pattern illustrated by investments which are the first to react, in particular the residential component, after the temporary fall due to the uncertainty shock. Our results are different from those of Jackson, Kliesen, and Owyang (2019), who do not document the same overshooting pattern, even if the responses of investment components are increasing after eight quarters and most probably the overshooting effects are only lagged in their exercise.

The increasing reponses of GDP components are also supported by the large asset purchase announcements by the Federal Reserve. As discussed in Weale and Wieladek (2016), thanks to the monetary injections operated by the monetary institution, households and firms are more confident about the role of the Federal Reserve to support the economy in both recessions and normal times. For this reason, the perceived volatility of future inflation and GDP will decline. Besides, both the BS movements and the reduction of the financial uncertainty can have one of two effects: a decline in consumers' uncertainty about durable consumption or a higher risk-taking by investors. These two channels can support the aggregate output by increasing consumption and reducing premia on risky lending.

Generalised Forecast Error Variance Decomposition. How important is the uncertainty in driving economic dynamics? To assess the importance of uncertainty shocks, we calculate the Generalised Forecast Error Variance Decomposition (GFEVD) for a one-standard deviation regime dependent shock to all variables using the Lanne and Nyberg (2016) 's algorithm. Table 1 reports the state-dependent 
12-quarters ahead GFEVD due to uncertainty shocks: 1) the financial uncertainty index estimated by Ludvigson, Ma, and Ng (2019) indicator (in the upper panel of the table) and (2) the VXO (in the lower panel of the table). We report the contribution of uncertainty shocks across regimes (normal times versus recessions) for each variable multiplied by 100 . The variables indicated in the first column are (from top to bottom): the inflation rate (Infl), the output growth (GDP), the consumption (Cons), the investments (Inv), the unemployment rate (Unempl), the federal fund rate (FFR), the total assets of the Fed balance sheet (BS), the 10year Treasury Bond (10-y TB), and the uncertainty. We compute the GFEVD for two alternative models: column "with Cons" reports the GFEVD of the specification augmented by the consumption and column "with Inv" reports those with the specification augmented by the investments. In the case of the financial uncertainty index $(\mathrm{FU})$, we note how the reaction of variables to uncertainty shocks is magnified in both alternative models during recessions. Specifically, as shown in the Table 1, the contribution of financial uncertainty is approximately from 4 to 6 times larger for macroeconomic variables (GDP, consumption, investments, and unemployment) and around 8 times larger for inflation during recessionary periods with respect to normal times. It is interesting to note how the contribution of financial uncertainty on the monetary variables (FFR, BS, 10-year TB) is from 7 to 12 times larger in recessions than in normal times. However, the forecast error variance of the uncertainty is largely explained by its own shock in both regimes. These findings are robust when we substitute the financial uncertainty indicator à la Ludvigson, Ma, and $\mathrm{Ng}$ (2019) with the VXO. This is not surprising, since the high correlation between the two proxies (0.79).

These findings are in line with the predictions documented by the theoretical framework in Basu and Bundick (2017) which show that the co-movements among output, consumption, and investments are one of the main features of the economy's response to an uncertainty shock. In particular, the evidence for investments is 
connected with previous studies which highlight that the level of uncertainty affects the value of investment opportunities in case of the irreversibility of invesment (i.e., Bernanke, 1983; Bloom, 2009; Bloom, Floetotto, Jaimovich, Saporta-Eksten, and Terry, 2018).

\section{Counterfactual Experiments}

\section{How effective are Balance Sheet-related monetary policies to offset uncertainty shocks?}

The answer to this question is important for understanding the role played by the

BS-related monetary policy in tackling the contractionary effects of an uncertainty shock.

We run a counterfactual exercise in which we shut down the reaction of our variable of interest to the shock. This means that we zero out the coefficients of the BS equation in our Smooth Transition VAR. In doing so, we allow the Federal Reserve to react to a financial uncertainty shock through only the short-term interest rate. 8 In this Section, we report results only for recessions, since the baseline model provides evidence of a reaction of the total assets of the Fed BS only during

\footnotetext{
${ }^{8}$ We run counterfactual simulations by zeroing out the coefficients of the BS equation in our VAR as done for the federal funds rate coefficient in Sims and Zha (2006) and Caggiano, Castelnuovo, and Nodari (2020). Another way to run the counterfactual is to create a fictitious shock to keep the balance sheet fixed to its pre-shock level. We follow the former strategy. We run this exercise, fixing the path of the 10-year TB. The long-term interest rate captures the expectation over future monetary policy and fixing its path allows us to capture its role in transmitting the effects of uncertainty shocks. Relying on a VAR model such as the Smooth Transition VAR, our counterfactual is subjected to Lucas (1976)'critique. In the VAR framework, we should adjust coefficients of both policy and non-policy equations to changes in policy. However, in the empirical VAR literature, there are several experiments which investigate different policy rules by "zeroing-out" the response of policy variables to shocks (B. S. Bernanke, Gertler, and Watson, 1997; Sims and Zha, 2006; Kilian and Lewis, 2011; Bachmann and Sims, 2012, among others). As discussed by Caggiano, Castelnuovo, and Nodari (2020), there could be a trade-off between how the counterfactual experiment is informative and how it satisfies the Lucas critique. For example, Rudebusch (2005) shows how the reduced-form VAR coefficients are relatively insensitive to changes in the VAR monetary policy rule. Meanwhile, Canova and Gambetti (2010) show how the properties of different measures of inflation expectations in the US are not influenced by breaks in monetary policy. In addition, they document similar reduced-form characteristics in the VAR models with and without expectations. These two examples support the possibility that a VAR analysis (like our counterfactual experiment) could be an indicative approximation about the ability of the monetary policy, in particular of the balance sheet, to tackle and stabilize the business cycle in recessions and normal times.
} 
recessionary periods.

Figure 6 plots the median of the GIRFs of our macroeconomic variables of interest from the baseline specification augmented with consumption (first column) or investments (second column) versus the counterfactual exercise. The solid and dotted lines refers to the GIRFs for the baseline and counterfactual scenarios, respectively. The difference between the reaction of macroeconomic variables from the baseline (augmented by consumption/investment) and from the counterfactual scenario represents the implementation of BS-related monetary policy measures.

We can note that the baseline and counterfactual scenarios produce similar reactions to financial shocks for the first few quarters after the shock occurs. This result is due to the relevance of initial conditions, which dominate during the first quarters. However, as time goes by, different policies start to exert a different impact on the evolution of the economic system. After 8 quarters, the BS-related monetary policies reduce the impact of the shock on GDP, consumption, inflation by $0.1 \%$ and on investment by $0.7 \%$. Thus, as shown in Figure 6 , when the BS is kept fixed, GDP goes down and unemployment goes up in both specification, remaining statistically far from zero for a prolonged period of time. The same holds when looking at the response of consumption and investments, where the difference is twice. Also, inflation displays the worst path when the BS is keept fixed. After 12 quarters, the macroeconomic variables are still below their pre-shock level. Two results stand out: 1) when the FED does not rely on the BS-related monetary policy, the effects of financial shocks become more persistent and 2) the macroeconomic effects of uncertainty become larger (in absolute value) than those derived from the baseline. We can conclude that in recessions the BS-related monetary policy tool is a powerful tool to mitigate economic downturns due to financial uncertainty shock.

There are numerous channels through which the BS-related monetary policy can affect the economy (see Bernanke, 2012). Weale and Wieladek (2016) highlight that when the balancing portfolio is the main channel, the reduction in long-term TB 
yields will be larger with respect to the short-term yields. From our results reported in Figure 3, uncertainty shocks have a greater impact on long-term than short-term rates. Therefore, we believe that BS-related monetary policies are transmitted to the economy through the portfolio's balance channel. This mechanism works via the acquisition of long-term TB (an activity of the Central Bank budget). Whether financial markets are segmented, for instance because agents may have preferred habitat for a given maturity in the government bond market, then the assets are not perfect substitutes in investors' portfolios. In this case, reducing government bond offerings, the Central Bank purchases increase bonds prices and reduce the return on those bonds (i.e., Gertler and Karadi, 2019; Chen, Cúrdia, and Ferrero, 2012). To achieve an effect beyond the government bond markets, such segmentation cannot be strong. If agents that sell government bonds to the Central Bank rebalance their investment portfolios by purchasing other securities (i.e, corporate bonds, shares, or securities guaranteed), then the prices for these assets will increase. This channel might lead to wealth effects from higher asset prices (that raise consumption) and lower borrowing costs (that increase investments). Thus, such monetary policy reaction to an uncertainty shock will increase GDP.

\section{Conclusion}

A novel empirical contribution is given by estimating a Smooth Transition VAR including macroeconomic variables, monetary policy tools, and financial uncertainty proxy for the US economy. We investigate the impact of the uncertainty shock scrutinizing the monetary policy stance. The nonlinearities allow us to disentangle the behavior of the macroeconomic variables in two periods: recessions and normal times. Uncertainty shock is found to trigger negative macroeconomic fluctuations across the business cycle. The empirical evidence shows how the balance sheet-related monetary policy has an important role in supporting the economy, 
mitigating the negative contractionary effects of the uncertainty shock, during the recessionary periods. These results are a generalization and can also be extended in the current pandemic crisis due to the COVID-19 uncertainty providing evidence on the role of the monetary policy institution in support of the economy to avoid worse recessionary effects. 


\section{References}

Aastveit, K.A., G.J. Natvik, and S. Sola (2017). "Economic Uncertainty and the Influence of Monetary Policy". Journal of International Money and Finance 76, pp. 50-67.

Adrian, T., R.K. Crump, and E. Moench (2013). "Pricing the Term Structure with Linear Regressions". Journal of Financial Economics 110, pp. 110-138.

Alessandri, P. and H. Muntaz (2019). "Financial Regimes and Uncertainty Shocks". Journal of Monetary Economics 101(C), pp. 31-46.

Angelini, G., E. Bachiocchi, G. Caggiano, and L. Fanelli (2019). "Uncertainty across volatility regimes". Journal of Applied Econometrics 34(3), pp. 437-455.

Auerbach, A. and Y. Gorodnichenko (2012). "Measuring the Output Responses to Fiscal Policy". American Economic Journal: Economic Policy 4(2), pp. 1-27.

Bachmann, R. and E.R. Sims (2012). "Confidence and the transmission of government spending shocks". Journal of Monetary Economics (59), pp. 235-249.

Baker, S., N. Bloom, and S.J. Davis (2016). "Measuring Economic Policy Uncertainty". Quarterly Journal of Economics 131(4), pp. 1593-1636.

Basu, S. and B. Bundick (2015). "Endogenous volatility at the Zero Lower Bound: Implications for Stabilization Policy". Federal Reserve, Bank of Kansas City, WP 15-01.

Basu, S. and B. Bundick (2017). "Uncertainty Shocks in a Model of Effective Demand". Econometrica 85.3, pp. 937-958.

Bekaert, G., M. Hoerova, and M. Lo Duca (2013). "Risk, Uncertainty and Monetary Policy". Journal of Monetary Economics 60, pp. 771-788.

Bernanke, B. S. (2012). "Monetary Policy since the Onset of the Crisis". Federal Reserve Bank of Kansas City Economic Symposium, Jackson Hole. 
Bernanke, B. S., M. Gertler, and M. Watson (1997). "Systematic monetary policy and the effects of oil price shocks". Brookings papers on economic activity, pp. 91157.

Bernanke, B.S. (1983). "Irreversibility, Uncertainty, and Cyclical Investment". The Quarterly Journal of Economics 98(41), pp. 85-106.

Bernanke, B.S. and M. Gertler (1989). "Agency Costs, NetWorth, and Business Fluctuations". American Economic Review 79(1), pp. 14-31.

Bernanke, B.S., M. Gertler, and S. Gilchrist (1999). "The Financial Accelerator in a Quantitative Business Cycle Framework". in Handbook of Macroeconomics, edited by J. Taylor and M. Woodford 1, pp. 1341-1393.

Bloom, N. (2009). "The Impact of Uncertainty Shocks". Econometrica, 77(3), pp. 623685.

Bloom, N., S. Bond, and J. Van Reenen (2007). "Uncertainty and Investment Dynamics". The Review of Economic Studies 74(2), pp. 391-415.

Bloom, N., M. Floetotto, N. Jaimovich, I. Saporta-Eksten, and S.J. Terry (2018). "Really Uncertain Business Cycles". Econometrica 86(3), pp. 1031-1065.

Bundick, B. and A.L. Herriford T. amd Smith (2017). "Forward Guidance, Monetary Policy Uncertainty, and the Term Premium". Federal Reserve, Bank of Kansas City, WP 17-0\%.

Cacciatore, M. and F. Ravenna (2020). "Uncertainty, Wages, and the Business Cycle". CEPR Discussion Paper No 14715.

Caggiano, G., E. Castelnuovo, V. Colombo, and G. Nodari (2015). "Estimating Fiscal Multipliers: News From a Nonlinear World". The Economic Journal 125(584), pp. $746-776$.

Caggiano, G., E. Castelnuovo, and N. Groshenny (2014). "Uncertainty Shocks and Unemployment Dynamics: An Analysis of Post-WWII U.S. Recessions". Journal of Monetary Economics 67, pp. 78-92. 
Caggiano, G., E. Castelnuovo, and G. Nodari (2020). "Uncertainty and monetary policy in good and bad times: A Replication of the VAR investigation by Bloom (2009)". University of Padova and Melbourne, mimeo.

Caggiano, G., E. Castelnuovo, and G. Pellegrino (2017). "Estimating the real effects of uncertainty shocks at the Zero Lower Bound". European Economic Review 100, pp. 257-272.

Canova, F. and L. Gambetti (2010). "Do Expectations Matter? The Great Moderation Revisited". American Economic Journal: Macroeconomics 2(3), pp. 183205.

Carriero, A., T. E. Clark, and M. Marcellino (2018). "Measuring Uncertainty and Its Impact on the Economy". Review of Economics and Statistics 100(5), pp. 799815.

Castelnuovo, E. (2019a). "Domestic and Global Uncertainty: A Brief Survey and Some New Results". CESifo Working Paper No.7900.

Castelnuovo, E. (2019b). "Yield Curve and Financial Uncertainty: Evidence Based on US Data". Marco Fanno WP 234.

Chen, H., V. Cúrdia, and A. Ferrero (2012). "The Macroeconomic Effects of LargeScale Asset Purchase Programmes". Economic Journal 122(564), pp. 289-315.

Chernozhukov, V. and H. Hong (2003). "An MCMC Approach to Classical Estimation". Journal of Econometrics 115(2), pp. 293-346.

Christiano, L.J., M. Eichenbaum, and C.L. Evans (2005). "Nominal Rigidities and the Dynamic eEffects of a Shock to Monetary Policies". Journal of Political Economy 113(1), pp. 1-45.

Colombo, V. (2013). "Economic Policy Uncertainty in the U.S.: Does it matter for the Euro area?" Economics Letters 121(1), pp. 39-42.

Colombo, V. and A. Paccagnini (2020). "Does the credit supply shock have asymmetric effects on macroeconomic variable?" Economics Letters 188, p. 108958. 
Curdia, V. and M. Woodford (2011). "The central-bank balance sheet as an instrument of monetary policy". Journal of Monetary Economics 58(1), pp. 5479.

Dahlhaus, T., K. Hess, and A. Reza (2018). "International Transmission Channels of U.S. Quantitative Easing: Evidence from Canada". Journal of Money, Credit and Banking 50(2), pp. 545-563.

Dell'Ariccia, G., P. Rabanal, and D. Sandri (2018). "Unconventional Monetary Policies in the Euro Area, Japan, and the United Kingdom". Journal of Economic Perspectives 32(4), pp. 147-172.

Dixit, A. K. and R. S. Pindyck (1994). "Investment Under Uncertainty". Princeton University Press.

Ferrara, L., S. Lhuissier, and F. Tripier (2018). "Uncertainty Fluctuations: Measures, Effects and Macroeconomic Policy Challenges". International Macroeconomics in the Wake of the Global Financial Crisis, pp. 159-181.

Gambacorta, L., B. Hofmann, and G. Peersman (2014). "The Effectiveness of Unconventional Monetary Policy at the Zero Lower Bound: A Cross-Country Analysis". Journal of Money, Credit and Banking 46(4), pp. 615-642.

Gertler, M. and P. Karadi (2019). "A Model of Unconventional Monetary Policy". Journal of Monetary Economics 58(1), pp. 17-34.

Gilchrist, S., J. W. Sim, and E. Zakrajsek (2014). "Uncertainty, Financial Frictions, and Investment Dynamics". National Bureau of Economic Research WP 20038.

Gürkaynak, R. S., B. Sack, and E. Swanson (2005). "The Sensitivity of Long Term Interest Rates to Economic News: Evidence and Implications for Macroeconomic Models". American Economic Review 95(1), pp. 425-436.

Jackson, L.E., K.L. Kliesen, and M.T. Owyang (2019). "The Nonlinear Effects of Uncertainty Shocks". Studies in Nonlinear Dynamics and Econometrics 20190024.

Jurado, K., S. C. Ludvigson, and S. Ng (2015). "Measuring Uncertainty". American Economic Review, 105(3), pp. 1177-1216. 
Kiley, M.T. (2018). "Quantitative Easing and the "New Normal" in Monetary Policy". Manchester School, University of Manchester 86(S1), pp. 21-49.

Kilian, L. and L.T. Lewis (2011). "Does the Fed respond to oil price shocks?" The Economic Journal 121, pp. 1047-1072.

Kiyotaki, N. and J. Moore (1997). "Credit Cycles". Journal of Political Economy 105, pp. 211-248.

Koop, G., M. Pesaran, and S. Potter (1996). "Impulse Response Analysis in Nonlinear Multivariate Models". Journal of Econometrics 74(1), pp. 119-148.

Lanne, M. and H. Nyberg (2016). "Generalized Forecast Error Variance Decomposition for Linear and Nonlinear Multivariate Models". Oxford Bulletin of Economics and Statistics 78(4), pp. 595-603.

Leduc, S. and Z. Liu (2016). "Uncertainty shocks are aggregate demand shocks". Journal of Monetary Economics 82(C), pp. 20-35.

Lucas, R. E. (1976). "Econometric policy evaluation: A critique". in CarnegieRochester conference series on public policy, Elsevier 1, pp. 19-46.

Ludvigson, S. C., S. Ma, and S. Ng (2019). "Uncertainty and Business Cycles: Exogenous Impulse or Endogenous Response?" American Economic Journal: Macroeconomics, forthcoming.

Meaning, J. and F. Zhu (2011). "The Impact of Recent Central Bank Asset Purchase Programmes". Bis Quarterly Review 1, pp. 73-83.

Nodari, G. (2014). "Financial Regulation Policy Uncertainty and Credit Spreads in the U.S." Journal of Macroeconomics 41, pp. 122-132.

Pastor, L. and P. Veronesi (2013). "Political uncertainty and risk premia". Journal of Financial Economics 110(3), pp. 520-545.

Peersman, G. (2011). "Macroeconomic Effects of Unconventional Monetary Policy in the Euro Area". ECB Working Paper No. $139 \%$. 
Rossi, B. and T. Sekhposyan (2015). "Macroeconomic Uncertainty Indices Based on Nowcast and Forecast Error Distributions ". American Economic Review Papers and Proceedings, 105(5), pp. 650-655.

Rudebusch, G. D. (2005). "Assessing the Lucas Critique in Monetary Policy Models". Journal of Money, Credit and Banking 37(2), pp. 245-272.

Sims, C.A. and T. Zha (2006). "Were there Regime Swithces in U.S. Monetary Policy?" American Economic Review 96(1), pp. 54-81.

Stock, J.H. and M.W. Watson (2012). "Disentangling the Channels of the 2007-2009 Recession". Brookings Papers on Economic Activity 43(1), pp. 81-156.

Stokey, N.L. (2016). "Wait-and-see: Investment options under policy uncertainty". Review of Economic Dynamics 21, pp. 246-265.

Teräsvirta, T. (1988). "Modelling Economic Relationships with Smooth Transition Regressions". In: Giles, D., Ullah, A., C. (Eds.), Handbook of Applied Economic Statistics, Dekker.

Teräsvirta, T. and Y. Yang (2014). "Linearity and Misspecification Tests for Vector Smooth Transition Regression Models". CREATES, Aarhus University, mimeo. Weale, M. and T. Wieladek (2016). "What are the macroeconomic effects of asset purchases?" Journal of Monetary Economics 79, pp. 81-93. 


\section{Tables}

Table 1: Generalized Forecast Error Variance Decomposition: contribution of uncertainty shocks across regimes

\begin{tabular}{ccc|cc} 
& \multicolumn{4}{c}{ FU } \\
\cline { 2 - 5 } & \multicolumn{2}{c}{ normal times } & \multicolumn{2}{c}{ Recession } \\
\cline { 2 - 5 } & with Cons & with Inv & with Cons & with Inv \\
\hline \hline Infl & 1.53 & 1.50 & 12.91 & 14.20 \\
GDP & 2.90 & 1.92 & 11.75 & 12.43 \\
Cons & 1.85 & - & 8.88 & - \\
Inv & - & 2.21 & - & 13.94 \\
Unempl & 8.19 & 6.35 & 22.66 & 25.66 \\
FFR & 4.14 & 2.90 & 19.50 & 20.54 \\
BS & 1.40 & 0.99 & 10.84 & 12.38 \\
10-y TB & 3.58 & 1.93 & 15.26 & 14.97 \\
Uncertainty & 62.88 & 55.39 & 65.41 & 74.95
\end{tabular}

\begin{tabular}{ccc|cc} 
& \multicolumn{4}{c}{ VXO } \\
\cline { 2 - 5 } & \multicolumn{2}{c}{ normal times } & \multicolumn{2}{c}{ Recession } \\
\cline { 2 - 5 } & with Cons & with Inv & with Cons & with Inv \\
\hline \hline Infl & 0.73 & 0.88 & 14.16 & 12.15 \\
GDP & 1.55 & 1.48 & 6.96 & 7.14 \\
Cons & 1.70 & - & 9.92 & - \\
Inv & - & 1.22 & - & 9.34 \\
Unempl & 1.72 & 3.14 & 25.00 & 23.89 \\
FFR & 1.23 & 2.11 & 15.16 & 14.15 \\
BS & 1.35 & 1.12 & 11.26 & 7.75 \\
10-y TB & 1.32 & 1.56 & 11.16 & 9.70 \\
Uncertainty & 74.95 & 70.78 & 77.35 & 78.12 \\
\hline \hline
\end{tabular}

Notes: The table reports the Generalized Forecast Error Variance Decomposition (GFEVD) at 12 quarters for uncertainty shocks proxied by: 1) the financial uncertainty indicator (FU) proposed by Ludvigson, Ma, and Ng (2019); and 2) by the VXO. The FEVD is estimated for 2 alternative models: column "with Cons" reports the GFEVD when the baseline specification is augmented by the consumption; column "with Inv" reports the ones when the baseline is augmented by the investments. The GFEVD is computed according to Lanne and Nyberg 's (2016) algorithm for a state-dependent 1-standard deviation shock to all variables. Each entry refers to the contribution of uncertainty shocks across regimes (normal times versus recessions) and for each endogenous variable, multiplied by 100 . The variables indicated in the first column are (from the top to the bottom): the inflation rate (Inf), the output growth (GDP), the consumption (Cons), the investments (Inv), the unemployment rate (Unempl), the federal fund rate (FFR), the total assets of the Fed balance sheet (BS), the 10-year treasury bill (10y-TB) and the uncertainty. 


\section{Figures}

Figure 1: Uncertainty measures vs Business cycle

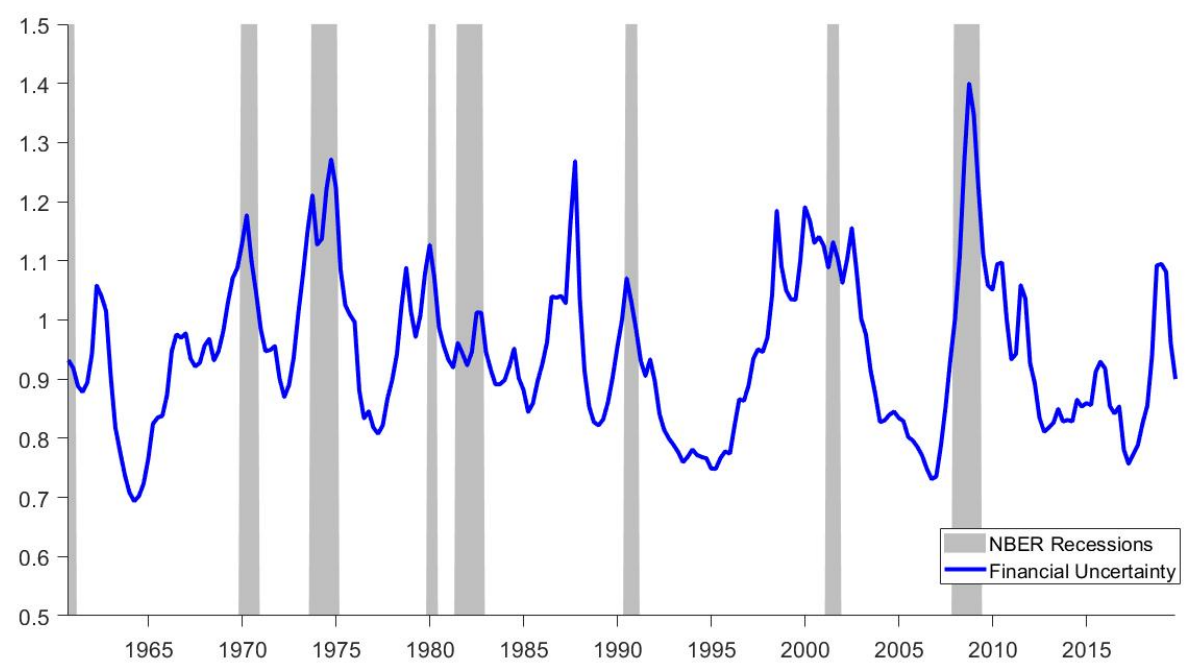

Notes: The shaded area indicate the U.S. recessionary phases (1960Q3-2019Q4), whereas the blue line refers to the uncertainty measure proposed by Ludvigson, Ma, and Ng (2019).

Figure 2: Transition function vs Business cycle

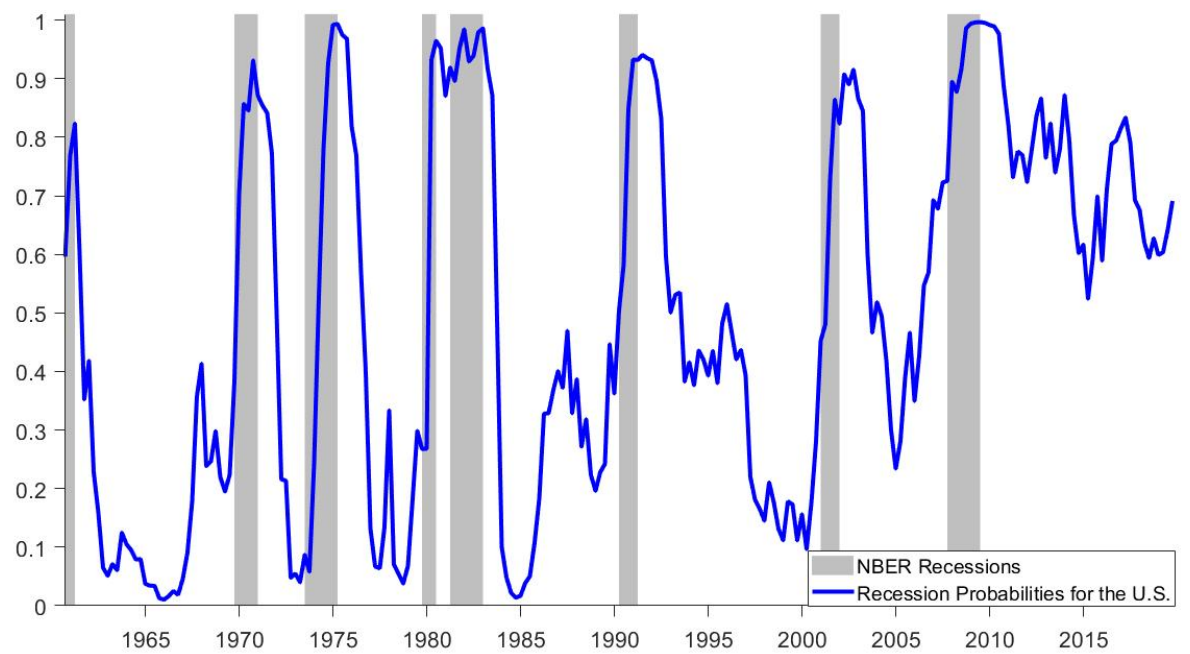

Notes: The shaded area indicate the U.S. recessionary phases (1960Q3-2019Q4), whereas the blue line refers to the backward looking 8-quarters moving average of GDP growth. 
Figure 3: Generalized impulse responses (GIRFs) to financial uncertainty shocks
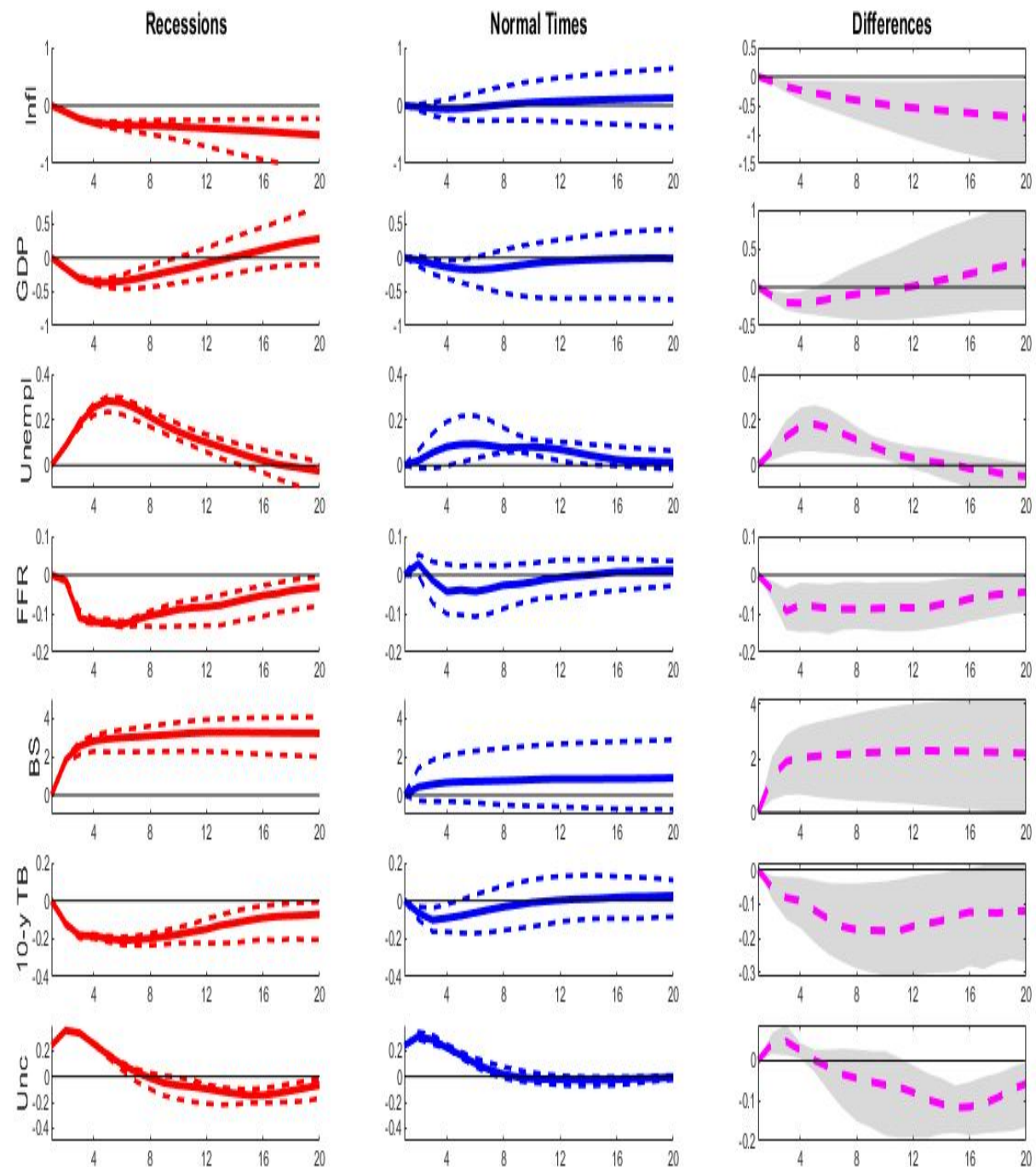

Notes: The figure reports the generalized impulse responses (GIRFs) to an unanticipated U.S. financial uncertainty shock in recessions (first column), in normal times (second columns), and the median realizations of the differences between generalized impulse responses in recessions and normal times (third column). Uncertainty proxied by the Ludvigson, Ma, and $\mathrm{Ng}$ (2019). The red and blue lines denote the median GIRFs in recessions and in normal times, respectively. The magenta lines refer to the median of the difference realizations between the two states of the world. Shaded bands denote confidence intervals at $68 \%$ levels. The variables are expressed in percent deviations with respect to their steady-state. The horizontal axis identifies quarters. 
Figure 4: Transmission mechanism: Consumption
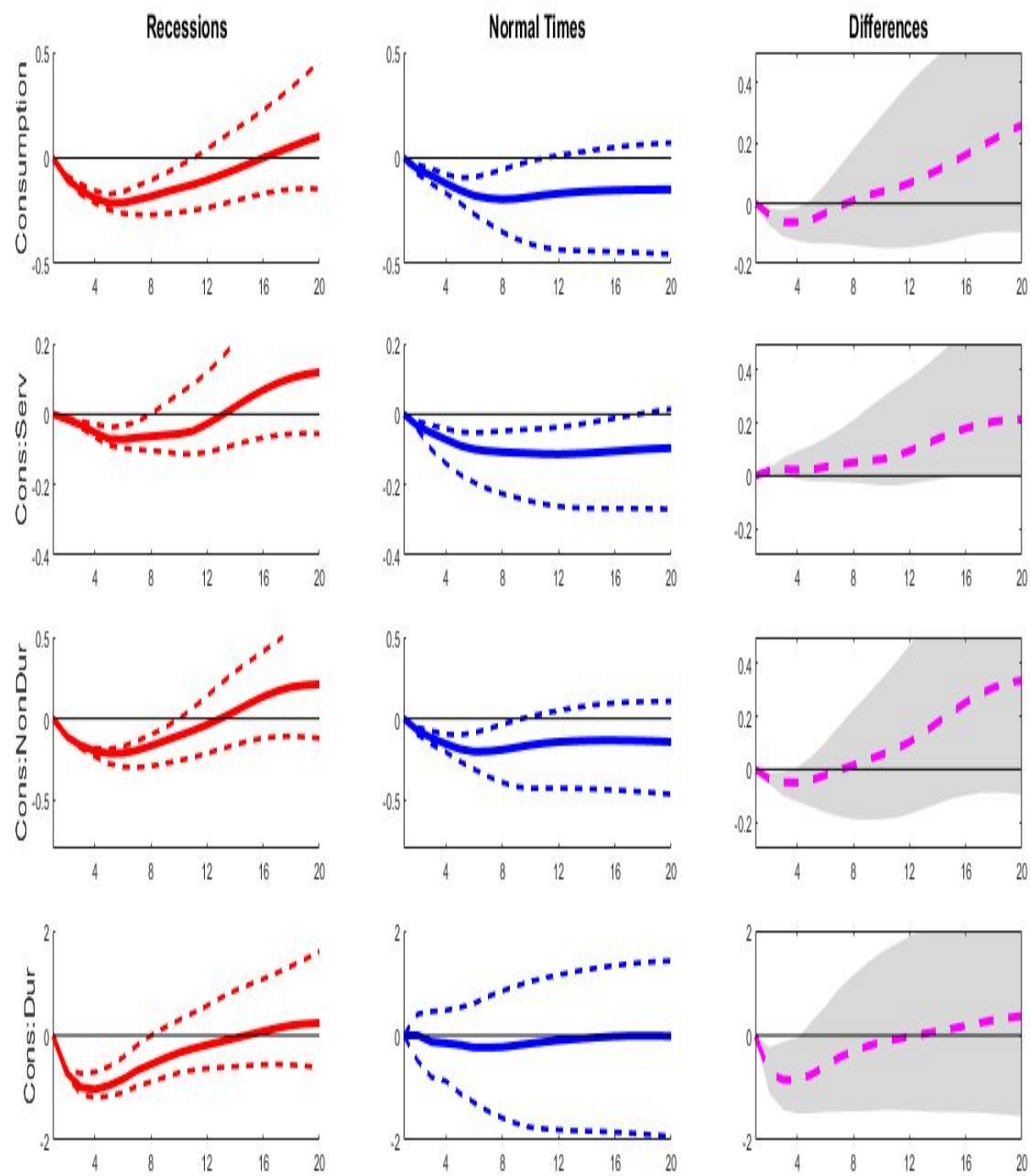

Notes: The figure reports the generalized impulse responses (GIRFs) to an unanticipated U.S. financial uncertainty shock for consumption (row 1) and some of its sub-components: consumption spending on services (row 2), non-durables (row 3), and durables (row 4). Uncertainty proxied by the Ludvigson, Ma, and Ng (2019)'s indicator. The red and blue lines denote the median GIRFs in recessions (first column) and in normal times (second column). The third column reports the median realizations of the differences between generalized impulse responses in recessions and normal times and the magenta lines refer to the median of the difference realizations between the two states of the world. Shaded bands denote confidence intervals at $68 \%$ levels. The variables are expressed in percent deviations with respect to their steady state. The horizontal axis identifies quarters. 
Figure 5: Transmission mechanism: Investments
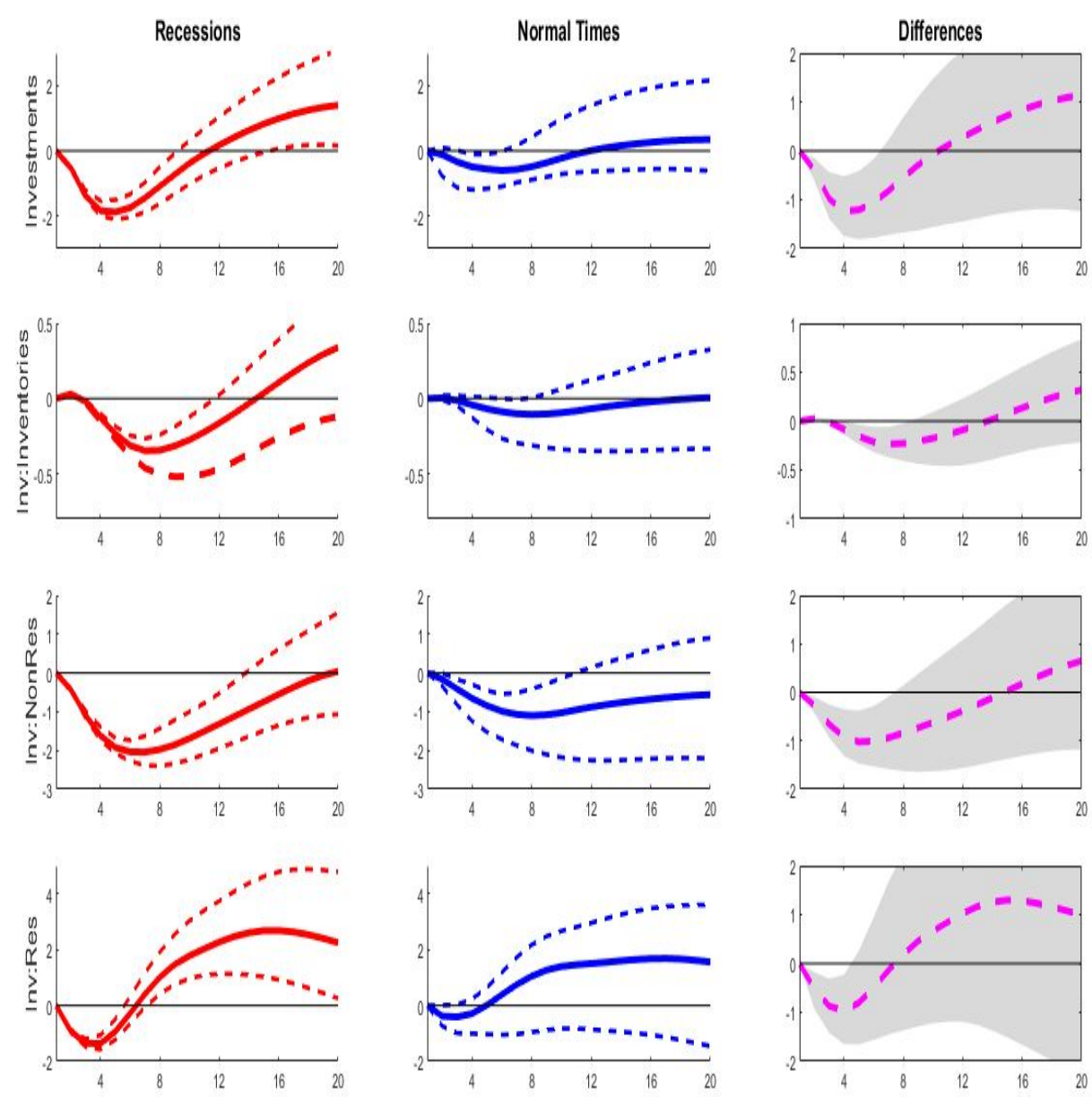

Notes: The figure reports the generalized impulse responses (GIRFs) to an unanticipated U.S. financial uncertainty shock for investments (row 1) and some of its sub-components: inventories (row 2), non-residential (row 3), and residential investment (row 4). Uncertainty proxied by the Ludvigson, Ma, and Ng (2019)'s indicator. The red and blue lines denote the median GIRFs in recessions (first column) and in normal times (second column). The third column reports the median realizations of the differences between generalized impulse responses in recessions and normal times and the magenta lines refer to the median of the difference realizations between the two states of the world. Shaded bands denote confidence intervals at $68 \%$ levels. The variables are expressed in percent deviations with respect to their steady state. The horizontal axis identifies quarters. 
Figure 6: Generalized Impulse Responses between with/without balance sheet channel
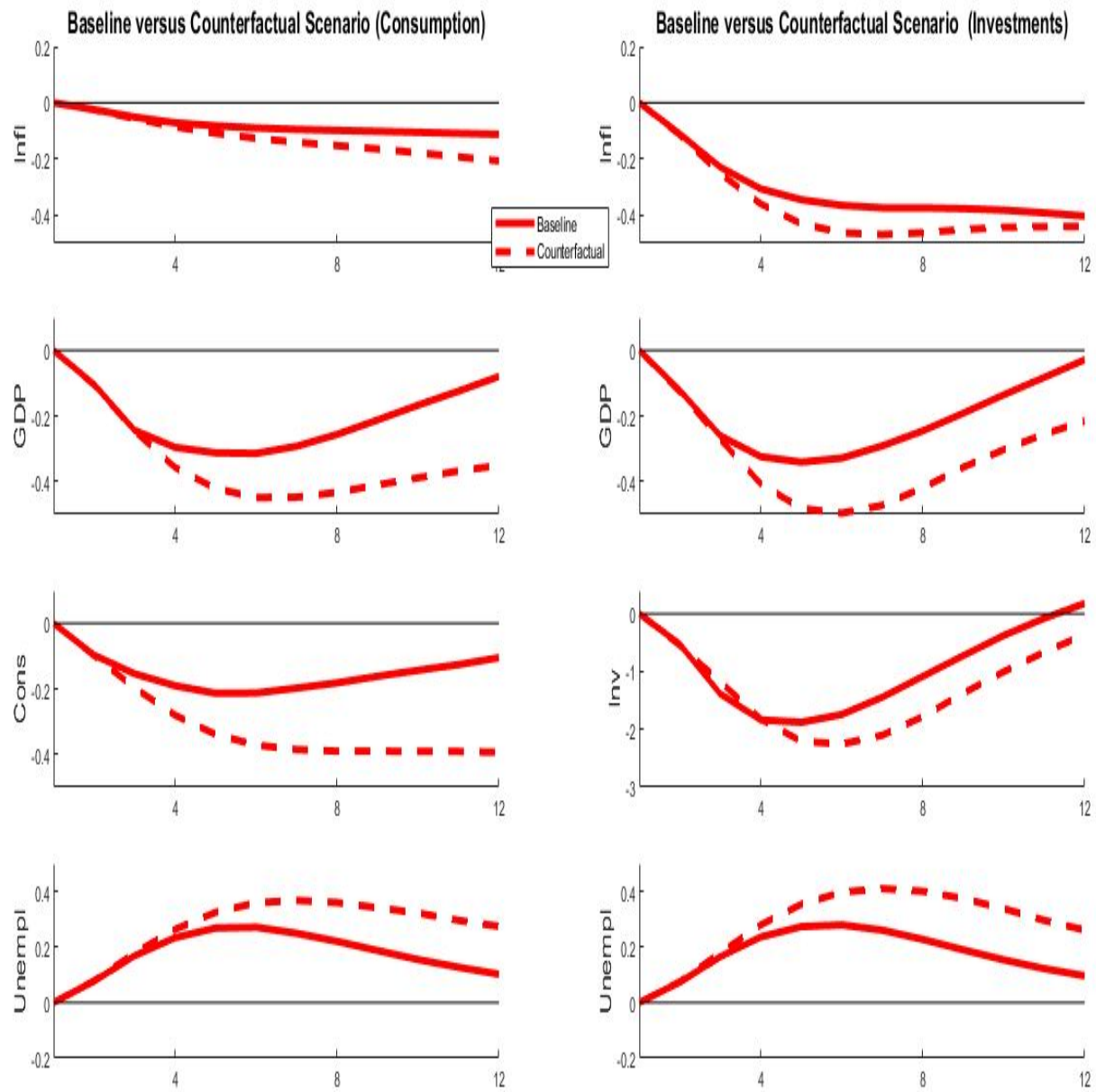

Notes: Both columns report the Generalised IRFs (median) in recessions from two scenarios: from our baseline specification (the red lines) and from the counterfactual one in which the total assets of the Fed BS channel is shut down (the red dotted lines). The left column reports the Girfs when the baseline specification is augmented by consumption, while the right column when the baseline specification is augmented by investments. Each row reports the results for inflation, GDP, consumption, investments, and unemployment. Uncertainty proxied by the Ludvigson, Ma, and $\mathrm{Ng}$ (2019) measure. The variables are expressed in percent deviations with respect to their steady-state. The horizontal axis identifies quarters. 


\section{Appendix}

This Appendix reports the estimation of the nonlinear VARs, the statistical evidence in favor of a nonlinear relationship between the endogenous variables included in the STVAR, and the computation of the Generalised Impulse Responses. In addition, we report the description of Robustness Checks implemented to assess the baseline results.

\section{A Linearity Test}

We test linearity versus nonlinearity applying the Teräsvirta and Yang (2014) test for Smooth Transition Vector AutoRegression (STVAR) with a single transition variable as in our framework. According to this test, we assume linearity under the null hypothesis versus a nonlinear model with a logistic smooth transition component under the alternative hypothesis. Let us assume a p-dimensional 2-regime approximate logistic STVAR model:

$$
\mathbf{X}_{t}=\mathbf{\Theta}_{o}^{\prime} Y_{t}+\sum_{i=1}^{n} \boldsymbol{\Theta}_{i}^{\prime} \mathbf{Y}_{t} z_{t}^{i}+\varepsilon_{t}
$$

where $\mathbf{X}_{t}$ is the $(p \times 1)$ vector of endogenous variables, $\mathbf{Y}_{t}=\left[\mathbf{X}_{t-1}|\ldots| \mathbf{X}_{t-k}\right]$ is the $(k \times p+q)$ vector of exogenous variables which includes lagged variables $(k)$ and a vector of constants. The transition variable is $z_{t}$, while $\boldsymbol{\Theta}_{0}$ and $\boldsymbol{\Theta}_{i}$ are matrices of parameters. In our empirical assessment, we have $p=9$ as the number of endogenous variables, $q=1$ as a number of exogenous variables, and $k=5$ as a number of lags. Under the null hypothesis of linearity, we assume $\mathbf{H}_{o}: \Theta_{i}=0 \forall i$. The Teräsvirta and Yang (2014) test features the following four steps:

1) We estimate the restricted model $\left(\mathbf{H}_{o}: \Theta_{i}=0 \forall i\right)$ by regressing $\mathbf{X}_{t}$ on $\mathbf{Y}_{t}$. We collect the residual $\tilde{\mathbf{E}}$ calculating the matrix for the residual sum of squares $R S S_{0}=\tilde{\mathbf{E}}, \tilde{\mathbf{E}}$.

2) We run an auxiliary regression of $\tilde{\mathbf{E}}$ on $\left(\mathbf{Y}_{t}, \mathbf{Z}_{n}\right)$ where the subscript $n$ indicates 
the n-order Taylor expansion of the transition function. We save the residuals $\tilde{\Xi}$ computing the matrix for the residual sum of squares $R S S_{1}=\tilde{\boldsymbol{\Xi}}, \tilde{\Xi}$.

3) We compute the test-statistic:

$$
L M=\operatorname{Ttr}\left[R S S_{0}^{-1}\left(R S S_{0}-R S S_{1}\right)\right]=T\left[p-\operatorname{tr}\left(R S S_{0}^{-1} R S S_{1}\right)\right]
$$

Under the null hypothesis, the test statistic is distributed as a $\chi^{2}$ with a number of degree of freedoms equals the number of restrictions, $p(k p+q)$. We compute two LM-type linearity tests fixing the value of the n-order of the Taylor expansion equal to $n=1$ and $n=3$ (as proposed by Lukkonen, Saikkonen, and Teräsvirta, 1988). In our estimation, $\mathrm{LM}=174$ and $\mathrm{LM}=414$ when $n=1$ and $n=3$, respectively. The corresponding $\mathrm{p}$-value in both tests is zero. In other words, our model presents nonlinear dynamics.

\section{B Estimation of the Non-linear VARs}

Our STVAR model (1)-(4) is estimated via maximum likelihood. The log - likelihood function is as follows:

$$
\log L=\mathrm{const}-\frac{1}{2} \sum_{t=1}^{T} \log \left|\boldsymbol{\Omega}_{t}\right|-\frac{1}{2} \sum_{t=1}^{T} \varepsilon_{t}{ }_{t} \boldsymbol{\Omega}^{-1} \varepsilon_{t},
$$

where the vector of residuals $\varepsilon_{t}=X_{t}-\left(1-F\left(z_{t}\right)\right) \Pi_{N T} X_{t-1}-F\left(z_{t}\right) \Pi_{R} X_{t-1}$. Our purpose is to estimate the parameters $\Psi=\left\{\Omega_{R}, \Omega_{N T}, \Pi_{R}(L), \Pi_{N T}(L)\right\}$, where $\Pi_{j}(L)=\left[\Pi_{j, 1}, \ldots, \Pi_{j, p}\right], j \in\{R, N L\}$.

Due to the high nonlinearity of the model its estimation is problematic using standard optimization procedures. Hence, as in Auerbach and Gorodnichenko (2012), we employ the procedure as described as follows.

Conditional on $\gamma, \Omega_{R}, \Omega_{N T}$, where $\gamma$ is the slope parameter calibrated as described in Section 3, the model is linear in $\Pi_{R}, \Pi_{N T}$. Hence, for a given guess on $\gamma, \Omega_{R}, \Omega_{N T}$, 
the coefficients $\Pi_{R}, \Pi_{N T}$ can be estimated by minimizing $\frac{1}{2} \sum_{t=1}^{T} \varepsilon_{t}^{\prime} \Omega^{-1} \varepsilon_{t}$. Hence, we can re-write the regressors as below.

Let $\mathbf{W}_{t}=\left[F\left(z_{t}\right) \mathbf{X}_{t-1}\left(1-F\left(z_{t}\right)\right) \mathbf{X}_{t-1} \ldots F\left(z_{t}\right) \mathbf{X}_{t-p}\left(1-F\left(z_{t}\right)\right) \mathbf{X}_{t-p}\right]$ be the extended vector of regressors, and $\boldsymbol{\Pi}=\left[\boldsymbol{\Pi}_{R}(L) \boldsymbol{\Pi}_{N T}(L)\right]$. Consequently, we can write $\varepsilon_{t}=$ $\mathbf{X}_{t}-\boldsymbol{\Pi} \mathbf{W}^{\prime}{ }_{t}$. In this case, the objective function becomes:

$$
\frac{1}{2} \sum_{t=1}^{T}\left(\mathbf{X}_{t}-\mathbf{\Pi} \mathbf{W}_{t}^{\prime}\right)^{\prime} \boldsymbol{\Omega}_{t}^{-1}\left(\mathbf{X}_{t}-\boldsymbol{\Pi} \mathbf{W}_{t}^{\prime}\right)
$$

We can show that the first order condition with respect to $\Pi$ is given by:

$$
\operatorname{vec} \boldsymbol{\Pi}^{\prime}=\left(\sum_{t=1}^{T}\left[\boldsymbol{\Omega}_{t}^{-1} \otimes \mathbf{W}_{t}^{\prime} \mathbf{W}_{t}\right]\right)^{-1} \operatorname{vec}\left(\sum_{t=1}^{T} \mathbf{W}_{t}^{\prime} \mathbf{X}_{t} \boldsymbol{\Omega}_{t}^{-1}\right)
$$

We iterate this procedure over different sets of values for $\left\{\Omega_{R}, \Omega_{N T}\right\}$ (conditional on a given value for $\gamma$ ). For each set of values, $\boldsymbol{\Pi}$ is obtained and the $\log L$ (B.1) is calculated.

Due to the high nonlinearity of the model in its parameters, we might get several local optima. Then, it is recommended to try different starting values of $\gamma$. To guarantee positive definiteness of the matrices $\Omega_{R}$ and $\Omega_{N T}$, we focus on the alternative vector of parameters $\Psi=\left\{\operatorname{chol}\left(\boldsymbol{\Omega}_{R}\right), \operatorname{chol}\left(\boldsymbol{\Omega}_{N T}\right), \boldsymbol{\Pi}_{R}(\mathrm{~L}), \boldsymbol{\Pi}_{N T}(L)\right\}$, where chol means the Cholesky decomposition.

We compute the confidence intervals using a Markov Chain Monte Carlo (MCMC) algorithm developed by Chernozhukov and Hong (2003) (CH hereafter). This methodology gives us both a global optimum and densities for the parameter estimates.

We implement the $\mathrm{CH}$ estimation via a Metropolis-Hastings algorithm. Given a starting value $\Psi^{0}$, the procedure constructs chains of length $N$ of the parameters of the estimated model following two steps:

Step 1: Draw a candidate vector of parameter values $\boldsymbol{\Theta}^{(n)}=\boldsymbol{\Psi}^{(n)}+\psi^{(n)}$ for the chain's $n+1$ state, where $\boldsymbol{\Psi}^{(n)}$ is the current state and $\psi^{(n)}$ is a vector of i.i.d. 
shocks drawn from $N\left(0, \boldsymbol{\Omega}_{\Psi}\right)$, and $\boldsymbol{\Omega}_{\Psi}$ is a diagonal matrix.

Step 2: Set the $n+1$ state of the chain $\Psi^{(n+1)}=\boldsymbol{\Theta}^{(n)}$ with $\min \left\{1, L\left(\boldsymbol{\Theta}^{(n)}\right) / L\left(\Psi^{(n)}\right)\right\}$, where $L\left(\boldsymbol{\Theta}^{(n)}\right)$ is the value of the likelihood function conditional on the candidate vector of parameter values, and $L\left(\Psi^{(n)}\right)$ is the value of the likelihood function conditional on the current state of the chain. Otherwise, set $\Psi^{(n+1)}=\Psi^{(n)}$.

The starting value $\boldsymbol{\Theta}^{(0)}$ is calculated using the second-order Taylor approximation of the model described from (1) to (4) in the Section 3, hence the model can be written as regressing $\mathbf{X}_{t}, \mathbf{X}_{t} z_{t}$, and $\mathbf{X}_{t} z_{t}^{2}$. We employ the residuals from this regression to fit the expression for the reduced-form time-varying variance-covariance matrix of the VAR (as explained in the main text) using maximum likelihood to estimate $\boldsymbol{\Omega}_{R}$ and $\boldsymbol{\Omega}_{N T}$.

We can construct $\Omega_{t}$, conditional on these estimates and given the calibration for $\gamma$. Conditional on $\boldsymbol{\Omega}_{t}$, we can compute the starting values for $\boldsymbol{\Pi}_{R}(L)$ and $\boldsymbol{\Pi}_{N T}(L)$ using equation (B.3).

Given the calibration for the initial (diagonal matrix) $\Omega_{\Psi}$, a scale factor is adjusted to generate an acceptance rate close to 0.3 , the typical value for these computational methods as pointed out by Canova (2007). The estimation accounts for $N=50,000$ draws and we use the last $20 \%$ for inference.

As described by $\mathrm{CH}, \boldsymbol{\Psi}^{*}=\frac{1}{N} \sum_{t=1}^{T} \boldsymbol{\Psi}^{(n)}$ is consistent estimate of $\boldsymbol{\Psi}$ under standard regularity assumptions on maximum likelihood estimators. The covariance matrix of $\boldsymbol{\Psi}$ is given by $V=\frac{1}{N} \sum_{t=1}^{T}\left(\Psi^{(n)}-\Psi^{*}\right)^{2}=\operatorname{var}\left(\boldsymbol{\Psi}^{(n)}\right)$, which is the variance of the estimates in the generated chain.

\section{Generalized Impulse Response Functions}


The Impulse Response Functions for the STVAR model are computed following the approach introduced by Koop, Pesaran, and Potter (1996) which propose an algorithm to calculate the Generalized Impulse Response Functions (GIRFs). The implementation of their procedure is composed of the following steps.

1) We construct the set of all possible histories $\boldsymbol{\Lambda}$ of length $p=12:\left\{\lambda_{i} \in \boldsymbol{\Lambda}\right\}$, where $\Lambda$ contain $T-p+1$ histories $\lambda_{i}$ and $T$ is the sample size $(T=312)$.

2) We separate the set of all recessionary histories from that of all normal time histories. We calculate the transition variable $z_{\lambda_{i}}$ for each $\lambda_{i}$. If $z_{\lambda_{i}} \leq z^{*}=-0.9 \%$, then $\lambda_{i} \in \Lambda^{R}$, where $\Lambda^{R}$ refers to all recessionary histories; if $z_{\lambda_{i}}>z^{*}=-0.9 \%$, then $\lambda_{i} \in \boldsymbol{\Lambda}^{N T}$, where $\boldsymbol{\Lambda}^{N T}$ refers to all normal time histories.

3) We select at random one history $\lambda_{i}$ from the set $\Lambda^{R}$, taking $\hat{\Omega}_{\lambda_{i}}$ obtained as follows:

$$
\hat{\mathbf{\Omega}}_{\lambda_{i}}=F\left(z_{\lambda_{i}}\right) \hat{\boldsymbol{\Omega}}_{R}+\left(1-F\left(z_{\lambda_{i}}\right)\right) \hat{\mathbf{\Omega}}_{N T}
$$

where $z_{\lambda_{i}}$ is the transition variable computed for the selected history $\lambda_{i} . \hat{\Omega}_{R}$ and $\hat{\Omega}_{N T}$ are calculated from the generated MCMC chain of the parameter values during the estimation step. As in Koop et al. (1996), we consider the distribution of parameters rather than their mean values to allow for parameter uncertainty.

4) We estimate the variance-covariance matrix $\hat{\Omega}_{\lambda_{i}}$ using the Cholesky-decomposition:

$$
\hat{\Omega}_{\lambda_{i}}=\hat{\mathbf{C}}_{\lambda_{i}} \hat{\mathbf{C}}_{\lambda_{i}}^{\prime}
$$

we orthogonalize the estimated residuals to get the structural shocks as:

$$
\mathbf{e}_{\lambda_{i}}^{(j)}=\hat{\mathbf{C}}_{\lambda_{i}}^{-1} \hat{\varepsilon}
$$

5) From $\mathbf{e}_{\lambda_{i}}$ draw with replacement $h$ nine-dimensional shocks and get the vector 
of bootstrapped shocks

$$
\mathbf{e}_{\lambda_{i}}^{(j) *}=\left\{\mathbf{e}_{\lambda_{i, t}}^{*}, \mathbf{e} *_{\lambda_{i, t+1}}^{*}, \ldots, \mathbf{e} *_{\lambda_{i, t+h}}^{*}\right\}
$$

where $h$ is the number of horizons for the IRFs we compute.

6) We form another set of bootstrapped shocks which are equal to (C.4) except for the $k_{t h}$ shock in $\mathbf{e}_{\lambda_{i}}^{(j) *}$ which is the shock we perturb by a $\delta$ amount. We call the vector of bootstrapped perturbed shocks as $\mathbf{e}_{\lambda_{i}}^{(j)^{\delta}}$.

7) We transform back $\mathbf{e}_{\lambda_{i}}^{(j) *}$ and $\mathbf{e}_{\lambda_{i}}^{(j)^{\delta}}$ as follows:

$$
\hat{\varepsilon}_{\lambda_{i}}^{(j) *}=\hat{\mathbf{C}}_{\lambda_{i}} \mathbf{e}_{\lambda_{i}}^{(j) *}
$$

and

$$
\hat{\varepsilon}_{\lambda_{i}}^{(j)^{\delta}}=\hat{\mathbf{C}}_{\lambda_{i}} \mathbf{e}_{\lambda_{i}}^{(j)^{\delta}}
$$

8) We use (C.5) and (C.6) to simulate the evolution of $\mathbf{X}_{\lambda_{i}}^{(j) *}$ and $\mathbf{X}_{\lambda_{i}}^{(j) \delta}$ and we construct the $\operatorname{GIRF}^{(j)}\left(h, \delta, \lambda_{i}\right)$ as $\mathbf{X}_{\lambda_{i}}^{(j) *}-\mathbf{X}_{\lambda_{i}}^{(j) \delta}$.

9) Conditional on history $\lambda_{i}$, repeat for $j=1, \ldots, B$ vectors of bootstrapped residuals and get $\operatorname{GIRF}^{1}\left(h, \delta, \lambda_{i}\right), \operatorname{GIRF}^{2}\left(h, \delta, \lambda_{i}\right), \ldots, \operatorname{GIRF}^{B}\left(h, \delta, \lambda_{i}\right)$. We set $B=500$.

10) We calculate the GIRF conditional on history $\lambda_{i}$ as:

$$
\hat{G I R F}^{(i)}\left(h, \delta, \lambda_{i}\right)=B^{-1} \sum_{j=1}^{B} G I R F^{(i, j)}\left(h, \delta, \lambda_{i}\right) .
$$

11) We repeat all previous steps for $i=1, \ldots, 500$ histories belonging to the set of recessionary histories, $\lambda_{i} \in \Lambda^{R}$, and we get $\operatorname{GIRF^{(1,R)}}\left(h, \delta, \lambda_{1, R}\right), G \hat{I R F^{(2, R)}}\left(h, \delta, \lambda_{2, R}\right)$, $\ldots, G \hat{I R F}{ }^{(500, R)}\left(h, \delta, \lambda_{500, R}\right)$ where the subscript $R$ means that we are conditioning upon recessionary histories.

12) We take the average and we get $G \hat{I R F}^{(R)}\left(h, \delta, \Lambda_{R}\right)$, which is the average GIRF 
under recessions.

13) We repeat all the previous steps from 3 to 12 for 500 histories belonging to the set of all normal times and we get $G \hat{I R} F^{(N T)}\left(h, \delta, \Lambda_{N T}\right)$.

14) We compute the $68 \%$ confidence bands for the IR by picking up for each horizon of each state, the $16 t h$ and $84 t h$ percentile of the densities $G \hat{I R F}^{([1: 500], R)}$ and $G \hat{I R F}^{([1: 500], N T)}$.

\section{Robustness checks}

We check the robustness of our findings against several perturbations of the baseline STVAR model. In particular, we focus on alternative i) calibration of smoothness parameters; ii) transition variable; iii) measures of uncertainty; iv) sample size; and v) specifications. Figure D.1 reports the median realizations of the differences between generalized impulse responses in recessions and normal times to an unanticipated financial uncertainty shock for inflation, GDP, and unemployment. Each row refers to an alternative specification of our baseline. For each specification, the figure shows the median of the difference from robustness checks (magenta lines) and its confidence intervals at $68 \%$ levels (shaded bands) against the median realizations of the differences from the baseline specification (cyan lines).

Smoothness parameters and transition variable. We calibrate the smoothness parameter to match the frequencies of the U.S. recessions obtained as identified by the NBER business cycle dates (15\% in our sample). To check the sensitivity of our results to alternative calibrations of the smoothness parameter, we (re)calibrate $\gamma$ to include in our sample a number of recessions ranging from $10 \%$ to $20 \%$. The probability of $10 \%$ refers to the minimum amount of observations each regime should contain (Hansen, 1999). The calibration implies a value of $\gamma=1.8$ or $\gamma=2.6$ to capture the probability of being in recessions equal to $10 \%$ and to $20 \%$, respectively. 
Figure D.1 plots the results when the probability of being in recessions is equal to $20 \%$ (row 1) and $10 \%$ (row 2).

Furthermore, we rely on a transition function $z_{t}$ defined as a standardized backward-looking eight moving average growth rate of GDP. We modify this specification choice by relying on a state indicator, $z_{t}$, which includes the six-term moving average of the quarterly growth rate of GDP. To do so, we re-calibrate the slope parameter $\gamma=1.8$ and $\bar{z}=-0.9 \%$ to match the $15 \%$ frequency of recessions in the sample as classified by the NBER.

Our estimated results from the above exercises turn out to be very similar to those obtained from the baseline.

Alternative measures of financial uncertainty. Our baseline VAR models the financial uncertainty indicator proposed by Ludvigson, Ma, and Ng (2019) as a measure of uncertainty. As already pointed out in Section 3, Ludvigson, Ma, and $\mathrm{Ng}$ (2019) construct the financial uncertainty indicator exploiting the different h-step ahead forecast errors. We re-estimate our baseline STVAR replacing the uncertainty proxy relied on forecasting horizon equals to 4 quarters (FU4q) instead of 1 quarter. The second row of Figure D.1 plots the robustness results for the recessionary and normal phases, respectively. The results show that qualitatively our baseline results are not affected by the horizon change. However, the forecast horizon of uncertainty measures quantitatively affects the macroeconomic effects of such shocks. Those results are in line with Ludvigson, Ma, and Ng (2019). They point out that when the forecast horizons of their measures increase, the macroeconomic effects of financial uncertainty increase too.

Another way of modeling uncertainty in the literature is through the VXO index, a forward-looking measure of implied volatility (i.e., Bloom, 2009; Caggiano, Castelnuovo, and Groshenny, 2014; Leduc and Liu, 2016). In our sample, the correlation between the financial uncertainty index $(\mathrm{FU})$ and the VXO is $0.79 .{ }^{9} \mathrm{We}$ ${ }^{9}$ The VXO is employed instead of the VIX since the VIX is available from 1990. The VXO is
from 1985:I, the standard deviation of stock market returns as in Bloom (2009). From 1986:I the 
replace the financial uncertainty with the VXO and re-run our estimates to check the robustness of our impulse responses. The magenta lines of Figure D.1 (row 3) refer to the GIRFs when the proxy for uncertainty is the VXO. The reaction of macroeconomic variables is short-lived and smaller than those found relying on the Ludvigson, Ma, and Ng (2019) index. Jurado, Ludvigson, and Ng (2015) provide evidence that the effects of uncertainty shocks might depend on the source of the shock and its duration. Moreover, they point out that the duration of a financial uncertainty shock is more persistent than that of the VXO. Our findings are qualitatively in line with Ludvigson, Ma, and $\mathrm{Ng}$ (2019).

Sample size and Great Recession. The baseline STVAR model is estimated on the sample from 1960Q3 to 2019Q4. The results concerning the asymmetric effects of financial shocks conditional on the state of the economy may be too heavily driven by the inclusion of the Great Recession period in our sample. We investigate this issue by repeating our analysis on a sample excluding the Great Recession, 1960Q3 to 2007Q3. Our findings are qualitatively in line with those from our baseline specification. Of course, the reaction of the macroeconomic aggregates is weaker, but it confirms the nonlinearity effects of uncertainty shock on macroeconomic variables. Even excluding the Great Recession from the sample, the Fed reacts to the shock relying on a balance-sheet related monetary policy. Indeed, the total assets held in the Fed's BS increase (0.5\%), and such reaction is statistically significant. ${ }^{10}$ The reaction of the FFR is in line with Evans, Fisher, Gourio, and Krane (2015) who find that uncertainty is important in studying the monetary policy pattern in the pre-ZLB period. Comparing the GIRFs from this exercise and that of the baseline (Figure D.2-row 1) an interesting picture emerges. Indeed, as in Basu and Bundick (2015), the presence of the Great Recession magnifies the effects of uncertainty shocks on macroeconomic variables.

VXO is from the Chicago Board of Options Exchange (CBOE).

${ }^{10}$ For the sake of brevity, we do not report the results in Figure D.2, but they are available upon request). 
Monetary policy indicators. In our baseline we proxy the monetary policy reaction relying on the FFR, the total assets of the Fed $\mathrm{BS}$, and the long-term interest rate. ${ }^{11}$ Another way to take into account the overall stance of monetary policy is relying on a shadow short rate (SSR), which tracks the effective federal funds rate very closely before the crisis, but can take a negative value once the ZLB is at work. Lombardi and Zhu (2018) constructs an SSR measure based on the dynamic-factor model. They extract factors explain co-movements of several variables linked to conventional and unconventional monetary policy tools (interest rate, monetary policy aggregates, assets, and liabilities of the Central Bank balance sheet) employed by the Fed, as proxies for the overall monetary policy stance. Such shadow rates describe the interest rate that may be observed in the absence of a ZLB environment. We run an exercise in which we replaced in $X_{t}$ the monetary policy indicators (FFR, BS, and 10-year TB) with the SSR provided by Lombardi and Zhu (2018). We estimate the sample from 1970Q1 to 2016Q2, depending on the availability of the SSR time series. ${ }^{12}$ Row 7 of Figure D.2 plots the results that are qualitatively in line with the baseline.

Furthermore, Gertler and Karadi (2015) finds that the one-year TB maturity is quite sensitive to monetary surprises and accounts for the term structure effects (i.e., forward guidance). Following Gertler and Karadi (2015), we proxy the short-term interest rate (FFR) with the one-year TB. Our baseline results remain unaffected by such exercise.

Factor STVAR. We identify the uncertainty shock relying on the factor model

\footnotetext{
${ }^{11}$ From December 2008, the interest rate hits the ZLB and the Federal Reserve starts to rely on unconventional monetary policy tools (i.e., large-scale asset purchases and forward guidance) to offset negative macroeconomic dynamics. An unconventional monetary policy is likely to affect the long-term interest rate. To take into account a such a monetary policy mechanism and to disentangle the effects of uncertainty shock on monetary policy tools, our specification includes proxies for standard and non-standard monetary policy, in addition to the long-term interest rate. Moreover, forward guidance affects the 10-year TB. For instance, Bernanke (2013) states: "Forward rate guidance affects longer-term interest rates primarily by influencing investors' expectations of future short-term interest rates." Since we include the 10-year TB in our specification, it should allow us accounting for quantitative easing and forward guidance.

${ }^{12}$ We thank Marco Lombardi and Feng Zhu for sharing the SSR series.
} 
structure. As illustrated by Bernanke, Boivin, and Eliasz (2005), we augment the Smooth Transition VAR, adding one factor that has the primary role of summarizing missing macro and financial variables in the baseline. The Factor Augmented Smooth Transition VAR (Factor STVAR) is estimated in a two-step procedure. In the first step, we extract one factor from the large macro and financial dataset (composed by 132 monthly time series) maintained by the Federal Reserve of St. Louis and introduced by McCracken and Ng (2016). Accordingly to the criterion of Bai and Ng (2002) and using the Principal Component Analysis (PCA), we extract seven common factors that maximize the explained variance of such time series (for technical details and data transformation, see Bernanke, Boivin, and Eliasz, 2005; McCracken and Ng, 2016). We employ the first factor which explains around $70 \%$ of the variability of the 10 most important macro and financial series. This factor is also highly correlated with the Chicago FED National Activity Index proposed by Stock and Watson (1999). In the second step, we include the factor in the set of endogenous variables in the first position to purge possible bias due to lack of information when we estimate the uncertainty shock as discussed in Bernanke, Boivin, and Eliasz (2005) and in Caggiano, Castelnuovo, and Groshenny (2014) for the Factor Augmented STVAR model. As shown in Figure D.2 (row 4), our baseline results are unaffected.

Cholesky ordering. The identification of uncertainty shocks is achieved via the Cholesky assumption ordering last the uncertainty indicator in the vector $X_{t}$. On the one hand, in doing so we "purge" the uncertainty indicator in our VAR from the contemporaneous movements of our macroeconomic indicators, thereby sharpening the identification of uncertainty shocks. On the other hand, the macroeconomic variables are forced to have a zero non-impact reaction to uncertainty shocks. To check the extent to which our Cholesky identification assumption may affect the results, we re-estimate an alternative specification in which the uncertainty indicator is ordered first. This specification implies that the financial uncertainty shock is 
predetermined to the other US macroeconomic variables. Figure D.2 (row 5) shows that our findings are robust when we change the order of the shock.

S\&P 500. The baseline specification relies on the assumption that our VAR contains enough information to isolate a second-moment financial shock. To control for first-moment financial shocks, we add a stock market index (S\&P500) to our vector of endogenous variables ordering it before the uncertainty indicator. According to Figure D.2 (row 6), our results are robust in this exercise. 
Figure D.1: Robustness analysis
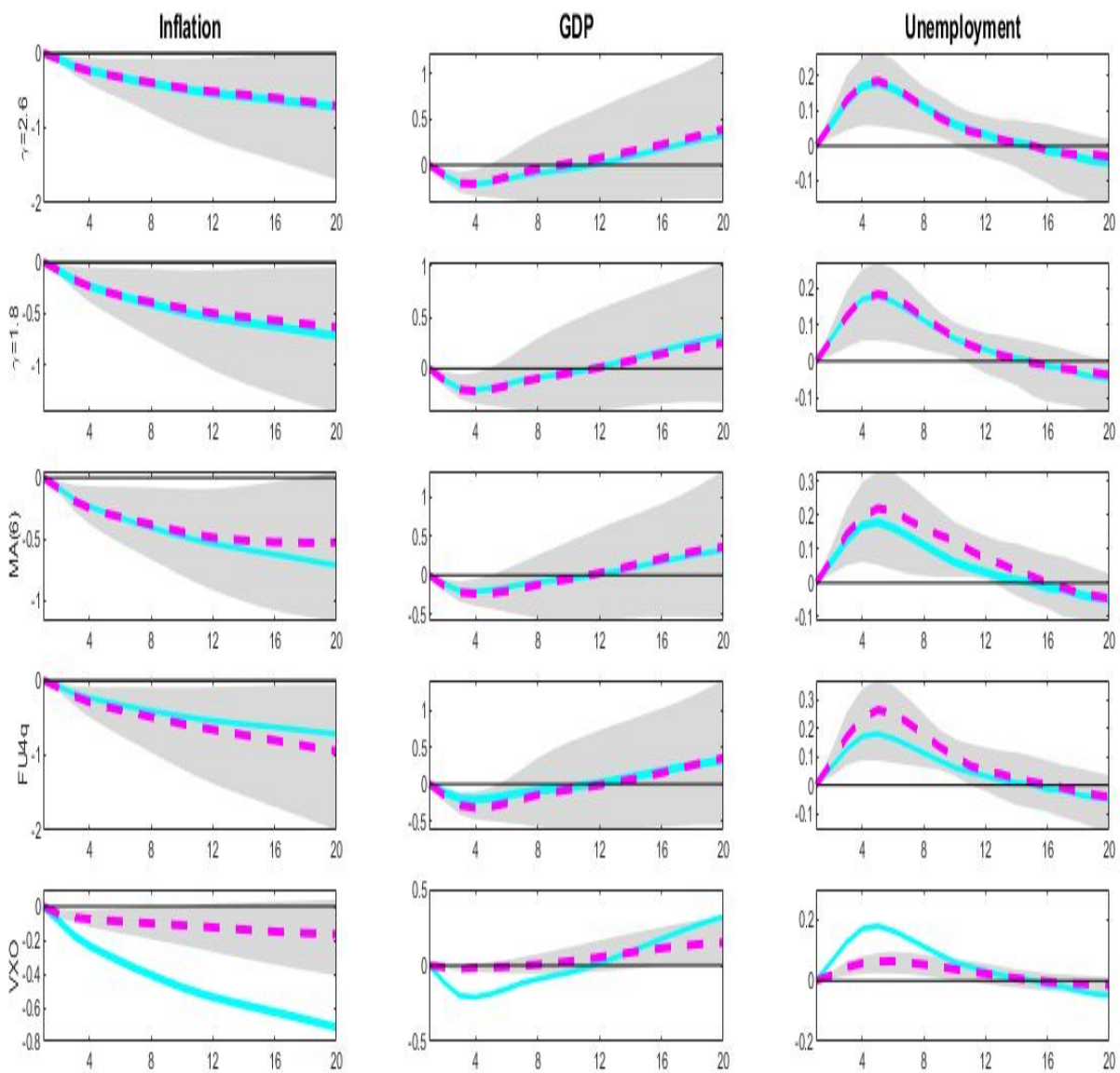

Notes: The figure reports the median realizations of the differences between generalized impulse responses in recessions and normal times to an uncertainty shock for inflation, GDP, and unemployment. Each row refers to an alternative specification of our baseline. For each specification the figure shows the median of the difference from the alternative specification (magenta lines) and its confidence intervals at $68 \%$ levels (shaded bands) against the median realizations of the differences from the baseline specification (cyan lines). From the top to the bottom: $\gamma=2.6$ and $\gamma=1.8$ refer to the probability of being in recessions equal to $20 \%$ and $10 \%$, respectively (rows 1 and 2); row 3 reports the estimation when we rely on six realizations of the quarter-on-quarter GDP growth rate; alternative indicators of uncertainty shock such as quarterly version of the 12-step ahead forecast uncertainty index constructed by Ludvigson, Ma, and Ng (2019) (FU4q in row 4), and the VXO (row 5). 
Figure D.2: Robustness analysis (cont'd)
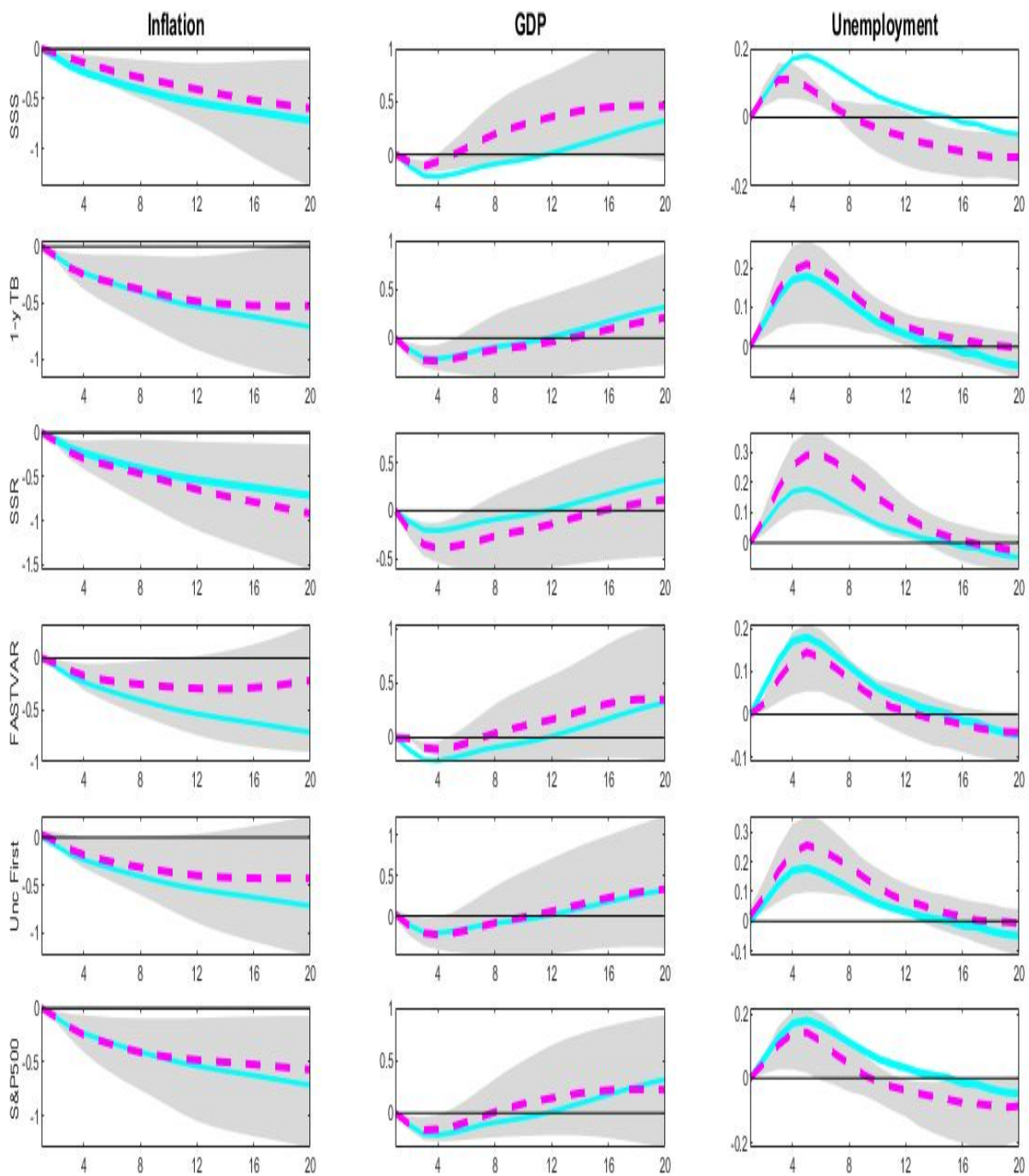

Notes: The figure reports the median realizations of the differences between generalized impulse responses in recessions and normal times to an uncertainty shock for inflation, GDP, and unemployment. Each row refers to an alternative specification of our baseline. For each specification the figure shows the median of the difference from the alternative specification (magenta lines) and its confidence intervals at $68 \%$ levels (shaded bands) against the median realizations of the differences from the baseline specification (cyan lines). From the top to the bottom: in row 1 we focus on a small sample size excluding from our sample the Great Recession (1970Q3 - 2007Q3); row 2 plots the results when we substitute the FFR with the 1 year Treasury bond; SSR refers to the inclusion of the Shadow short rate (Lombardi and Zhu, 2018); in row 4 we include a factor in the vector $X_{t}$ to improve the identification of the shock; row 5 reports when we order uncertainty first in the vector $X_{t}$, whereas row 6 when the S\&P500 is added to $X_{t}$ to exclude a first moment financial shock. 


\section{References}

Bai, J. and S. Ng (2002). "Determining the Number of Factors in Approximate Factor Models". Econometrica 70.1, pp. 191-221.

Basu, S. and B. Bundick (2015). "Endogenous volatility at the Zero Lower Bound: Implications for Stabilization Policy". Federal Reserve, Bank of Kansas City, WP 15-01.

Bernanke, B.S. (2013). "Communication and Monetary Policy". Speech on November 19.

Bernanke, B.S., J. Boivin, and P. Eliasz (2005). "Measuring the Effects of Monetary Policy: A Factor-Augmented Vector Autoregressive (FAVAR) Approach". The Quarterly Journal of Economics 120.1, pp. 387-422.

Bloom, N. (2009). "The Impact of Uncertainty Shocks". Econometrica, 77(3), pp. 623685.

Caggiano, G., E. Castelnuovo, and N. Groshenny (2014). "Uncertainty Shocks and Unemployment Dynamics: An Analysis of Post-WWII U.S. Recessions". Journal of Monetary Economics 67, pp. 78-92.

Evans, C., D.M. Fisher, F. Gourio, and S. Krane (2015). "Risk Management for Monetary Policy Near the Zero Lower Bound". Federal Reserve, Bank of Chiacago, WP 15-03.

Gertler, M. and P. Karadi (2015). "Monetary Policy Surprises, Credit Costs, and Economic Activity". American Economic Journal: Macroeconomics 7(1), pp. 4476.

Hansen, B. (1999). "Testing for Linearity". Journal of Economic Surveys 13(5), pp. $551-576$.

Jurado, K., S. C. Ludvigson, and S. Ng (2015). "Measuring Uncertainty". American Economic Review, 105(3), pp. 1177-1216. 
Leduc, S. and Z. Liu (2016). "Uncertainty shocks are aggregate demand shocks". Journal of Monetary Economics 82(C), pp. 20-35.

Lombardi, M.J. and F. Zhu (2018). "A Shadow Policy Rate to Calibrate U.S. Monetary Policy at the Zero Lower Bound". International Journal of Central Banking 14(5), pp. 305-346.

Ludvigson, S. C., S. Ma, and S. Ng (2019). "Uncertainty and Business Cycles: Exogenous Impulse or Endogenous Response?" American Economic Journal: Macroeconomics, forthcoming.

McCracken, M.W. and S. Ng (2016). "Fred-MD: A Monthly Database for Macroeconomic research". Journal of Business and Economic Statistics 34(4), pp. 574589.

Stock, J. and M. Watson (1999). "Forecasting inflation". Journal of Monetary Economics 44.2, pp. 293-335. 